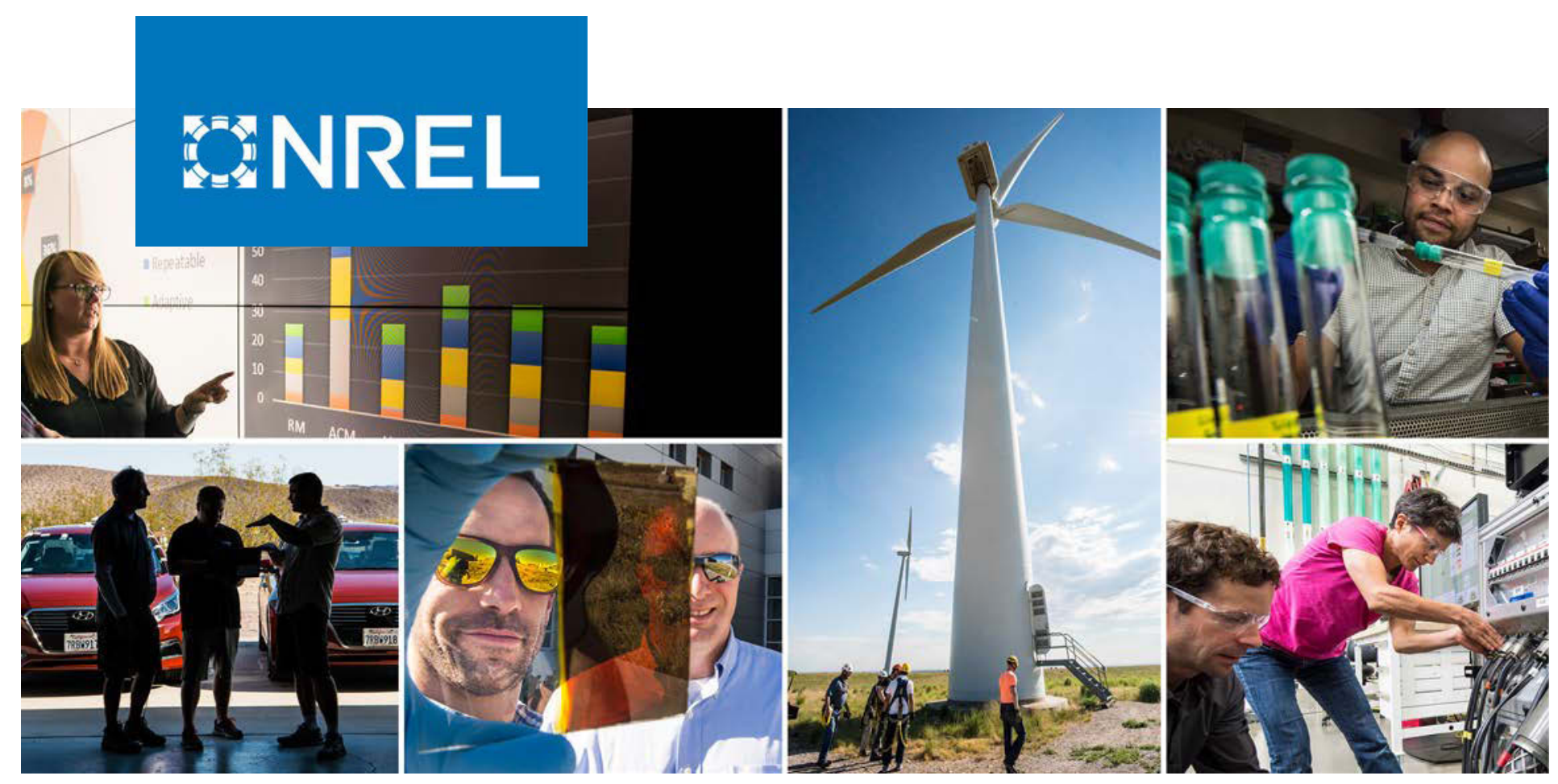

\title{
Absorbing the Sun: Operational Practices and Balancing Reserves in Florida's Municipal Utilities
}

Elaine Hale and Ella Zhou

National Renewable Energy Laboratory

Produced under direction of Nhu Energy, Inc. by the National Renewable Energy Laboratory (NREL) under Funds-In Agreement FIA-17-1857

NREL is a national laboratory of the U.S. Department of Energy Office of Energy Efficiency \& Renewable Energy

Operated by the Alliance for Sustainable Energy, LLC

This report is available at no cost from the National Renewable Energy Laboratory (NREL) at www.nrel.gov/publications.
Strategic Partnership Project Report NREL/TP-6A20-79385

July 2021 


\title{
GNREL
}

\section{Absorbing the Sun: Operational Practices and Balancing Reserves in Florida's Municipal Utilities}

\author{
Elaine Hale and Ella Zhou
}

National Renewable Energy Laboratory

\section{Suggested Citation}

Hale, Elaine and Ella Zhou. 2021. Absorbing the Sun: Operational Practices and Balancing Reserves in Florida's Municipal Utilities. Golden, CO: National Renewable Energy Laboratory. NREL/TP-6A20-79385. https://www.nrel.gov/docs/fy21osti/79385.pdf.

NREL is a national laboratory of the U.S. Department of Energy Office of Energy Efficiency \& Renewable Energy Operated by the Alliance for Sustainable Energy, LLC

This report is available at no cost from the National Renewable Energy Laboratory (NREL) at www.nrel.gov/publications.

Contract No. DE-AC36-08GO28308
Strategic Partnership Project Report NREL/TP-6A20-79385 July 2021

National Renewable Energy Laboratory 15013 Denver West Parkway Golden, CO 80401 303-275-3000 • www.nrel.gov 


\section{NOTICE}

This work was authored by the National Renewable Energy Laboratory, operated by Alliance for Sustainable Energy, LLC, for the U.S. Department of Energy (DOE) under Contract No. DE-AC36-08GO28308. Research commissioned by Nhu Energy, Inc. under Funds-In Agreement FIA-17-1857. Funding provided by the DOE Office of Energy Efficiency and Renewable Energy Solar Energy Technologies Office. The views expressed herein do not necessarily represent the views of the DOE or the U.S. Government.

This report is available at no cost from the National Renewable Energy Laboratory (NREL) at www.nrel.gov/publications.

U.S. Department of Energy (DOE) reports produced after 1991 and a growing number of pre-1991 documents are available free via www.OSTI.gov.

Cover Photos by Dennis Schroeder: (clockwise, left to right) NREL 51934, NREL 45897, NREL 42160, NREL 45891, NREL 48097, NREL 46526.

NREL prints on paper that contains recycled content. 


\section{Acknowledgments}

This work was supported by the U.S. Department of Energy Office of Energy Efficiency and Renewable Energy Solar Energy Technologies Office, as part of a wider project led by Nhu Energy, Inc. The authors would specifically like to thank Michele Boyd and Garrett Nilsen (U.S. Department of Energy) for supporting this and other SEEDS2-SES ${ }^{1}$ projects, Rick Meeker (Nhu Energy, Inc.) for leading the Florida Alliance for Accelerating Solar and Storage Technology Readiness (FAASSTeR) project, and the entire FAASSTeR team for their overall engagement and review of early versions of this work (Table 1). The Florida Municipal Electric Association (FMEA) also took a leading role in pulling the FAASSTeR project together and conducting outreach, including a companion webinar. ${ }^{2}$

Table 1. FAASSTeR Core Team Members

\begin{tabular}{ll}
\hline FAASSTeR Organization & Key Contacts \\
\hline Nhu Energy, Inc. & Rick Meeker, Anna Brinck \\
Florida Municipal Electric Association (FMEA) & Amy Zubaly, Nicole Albers \\
Florida Municipal Power Agency (FMPA) & Ann Beckwith, Susan Schumann \\
JEA & $\begin{array}{l}\text { René Brown, Mary Moran, Melinda Fischer, } \\
\text { Steve Mclnall }\end{array}$ \\
Orlando Utilities Commission (OUC) & Justin Kramer, Paul Brooker, Rubin York \\
Lakeland Electric & Scott Bishop, Paul Shipps, Willie Mathis \\
City of Tallahassee Electric \& Gas Utility (TAL) & Ben Cowart, Ella Isfahani, Michael Ohlsen \\
Gainesville Regional Utilities (GRU) & Milvia Hidalgo, Tom Boyer \\
Southern Alliance for Clean Energy & Bryan Jacob, John Wilson \\
Florida Office of Energy & Sean White \\
Lawrence Berkeley National Laboratory & Andrew Mills, Pía Rodriguez \\
\hline
\end{tabular}

This analysis would not have been possible without key data sources assembled in part by the authors' colleagues at the National Renewable Energy Laboratory (NREL). We would like to thank Michael Rossol for making the solar data used in this study available through the Renewable Resource and Power Data (R2PD) tool; Grant Buster, Clayton Barrows, and Karen $\mathrm{Yu}$ for their work on GridDB; Mike Meshek and the NREL Communications Office for helping pull together the Florida municipal utility operational questionnaire; and Adria Brooks and Shen Wang for their assistance on NREL's broader work on the FAASSTeR project. Joshua Novacheck provided valuable insight into best modeling practices for estimating reserve requirements. Donna Heimiller provided historical load forecast error data via the ABB Energy Velocity Suite. We are grateful for all these contributions and the joyful collegiality with which they were made.

\footnotetext{
${ }^{1}$ SEEDS2-SES is the Solar Energy Evolution and Diffusion Studies 2 - State Energy Strategies program. For information about the program, see https:/www.energy.gov/eere/solar/solar-energy-evolution-and-diffusion-studies2-state-energy-strategies-seeds2-ses.

${ }^{2}$ Slides from the webinar are available at https://www.nrel.gov/docs/fy21osti/78306.pdf.
} 
The FAASSTeR project utilities' operations teams provided crucial insight that made this work possible. Gainesville Regional Utilities, especially Milvia Hidalgo, Scott Callaway, Vic Dogra, and Kevin Wright welcomed us into their control room, all of the utilities filled out an operational questionnaire, and JEA staff Garry Baker, Craig Clevenger, and Paul Davis provided especially close review of our analysis results. We deeply appreciate their hospitality and engagement with this work. We thank reviewers Joshua Novacheck, Eduardo Ibanez, Paul Brooker, Daniel Steinberg, and Michele Boyd for comments that improved this report, and Michael Deneen for excellent editing support. 


\begin{tabular}{ll} 
Acronym List \\
AGC & automatic generation control \\
BA & balancing authority \\
CAISO & California Independent System Operator \\
CEM & capacity expansion model \\
DA & day-ahead \\
EIA & U.S. Energy Information Administration \\
FAASSTeR & Florida Alliance for Accelerating Solar and Storage Technology Readiness \\
FERC & Federal Energy Regulatory Commission \\
FMEA & Florida Municipal Electric Association \\
FMPA & Florida Municipal Power Agency \\
FMPP & Florida Municipal Power Pool \\
FPC & Duke Energy Florida \\
FPL & Florida Power \& Light \\
FRCC & Florida Reliability Coordinating Council \\
GRU & Gainesville Regional Utilities \\
GVL & Gainesville Regional Utilities EIA BA identifier \\
GW & gigawatt \\
GWh & gigawatt-hour \\
HA & hour-ahead \\
MISO & Midcontinent Independent System Operator \\
MUNIS & aggregation of GVL, TAL, JEA, and FMPP \\
MW & megawatt \\
MWh & megawatt-hour \\
NERC & North American Electric Reliability Corporation \\
NREL & National Renewable Energy Laboratory \\
OUC & Orlando Utilities Commission \\
PV & photovoltaic \\
R2PD & Renewable Resource and Power Data tool \\
SCED & security-constrained economic dispatch \\
SEC & Seminole Electric Cooperative \\
SH & sub-hourly \\
SIND & Solar Integration National Dataset \\
TAL & City of Tallahassee Electric \& Gas Utility \\
TEC & Tampa Electric Company \\
TWh & terawatt-hour \\
UC & unit commitment \\
WIND & Wind Integration National Dataset \\
& \\
\hline
\end{tabular}




\section{Executive Summary}

The vertically integrated investor-owned utilities, municipal utilities, and co-ops operating in the Florida Reliability Coordinating Council (FRCC) are expected to continue their current trend of procuring more solar photovoltaic (PV) capacity in response to PV price declines and city-level renewable energy goals. The municipal utilities participating in the Florida Alliance for Accelerating Solar and Storage Technology Readiness (FAASSTeR) project are no exception and may face distinctive PV integration challenges because their power system sizes are relatively small. In service of the FAASSTeR project, this study seeks to quantify the particular challenges that the four FRCC municipal balancing authorities - Gainesville Regional Utilities (GVL), City of Tallahassee Electric \& Gas Utility (TAL), JEA, and the Florida Municipal Power Pool (FMPP) - may have regarding increasing balancing reserve needs, as well was the potential impact of two mitigation strategies: increased operational frequency and coordinated operations.

This study analyzes the relationship between PV penetration and reserve needs by constructing data sets of historical load shapes paired with time-synchronous solar generation profiles simulated to contain different amounts of available generation per unit of annual load. Load and solar forecast errors are then estimated for different timescales. Depending on assumed operational practice, day-ahead (DA) forecasts and dispatch, hour-ahead (HA) forecasts and dispatch, or sub-hourly ( $\mathrm{SH})$ forecasts and dispatch, reserve requirements are estimated by covering a certain percentage of forecast errors for forecasts with the appropriate amount of look-ahead (e.g., day-ahead for DA, hour-ahead for HA). We explore the impact of system size and operational practice through the lens of eight FRCC balancing authorities (BAs) - GVL, TAL, JEA, Seminole Electric Cooperative (SEC), FMPP, Tampa Electric Company (TEC), Duke Energy (FPC), and Florida Power \& Light (FPL) - and two fictitious "reserve sharing groups"MUNIS (GVL, TAL, JEA, and FMPP) and FRCC (all BAs except SEC).

Given our focus on municipal utilities and the desire to map out the relationships between reserve requirements, PV generation and operational practice-especially for small BAs, which are less described in the relevant literature-our results focus on the steps a small BA like GVL could take to integrate increasing amounts of solar (we explore up to 30\% PV). Most of these steps are potentially relevant to the other Florida municipal BAs (TAL, JEA, and FMPP) as well; however, GVL, as one of the smallest BAs (only TAL is of similar size) and as a BA that relies primarily on day-ahead forecasting of load as well as day-ahead commitment and dispatch decisions, may have the most to gain from improved operational practices. (TAL, in contrast, uses hour-ahead load forecasts and dispatch to update its day-ahead priors.) Overall, we find:

- Moving from day-ahead to hour-ahead load forecasting, solar forecasting, and system dispatch could enable FRCC's smallest municipal balancing authority, GVL, to incorporate about $30 \%$ solar generation with median reserves around $20 \%$ instead of $30 \%$ to $60 \%$ of load. (Median day-ahead reserves of $60 \%$ reflect the conservative, low-data solar forecasting methodology used in this study, while the $30 \%$ lower bound reflects $75 \%$ improvement on that benchmark, as may be achievable with weather forecast-based solar forecasts.)

- If all Florida municipal utilities collectively procured operational reserves, this could again approximately halve GVL's reserve requirements at 30\% solar generation, reducing the median requirements to about $10 \%$ of load. For comparison, the median reserve needs 
of an "FRCC" reserve sharing group at 30\% solar generation would be about $6 \%$ of load (all else equal).

- Reserve needs vary greatly depending on how much forecast uncertainty is directly mitigated with reserves procurement. For example, if all Florida municipal utilities collectively procured operational reserves and had a PV penetration of about $30 \%$, the median reserve requirements could be anywhere from $5.5 \%$ to $14 \%$ of load, if reserve levels are selected to cover $80 \%$ to $99 \%$ of forecast errors. This range overlaps with the analogous range for all of FRCC analyzed together, which is 3.5\% to $9.0 \%$ of load.

Although we did not analyze reserve requirements from a rigorous, BA-specific North American Electric Reliability Corporation (NERC) reliability perspective and used conservative, low-data "persistence" forecasts (i.e., no weather forecast information) when historical data on forecast errors were not available, this analysis demonstrates clear, quantified trends that can help guide utility decisions regarding operational changes in support of PV integration. Solar forecasting, operational forecast and dispatch frequency, and operational footprint are first-order drivers of reserve need with increasing PV capacity. It appears that BAs of all sizes have options for integrating more solar with affordable reserve costs relative to current practice. 


\section{Table of Contents}

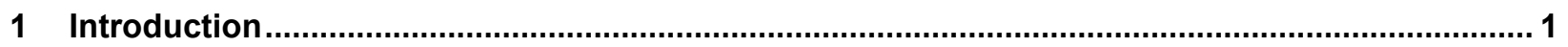

2 Large System Operational Practices and Implications for Balancing Reserves ......................... 3

3 Florida Municipal Utilities' Operational Practices .................................................................. 5

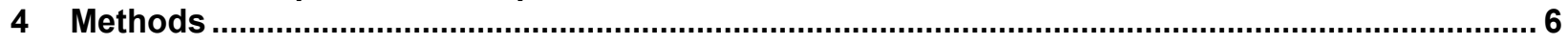

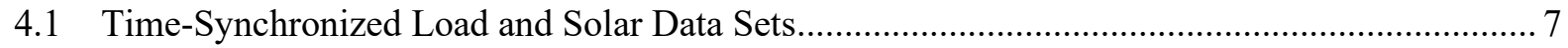

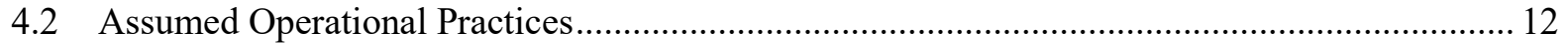

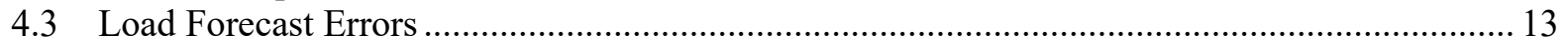

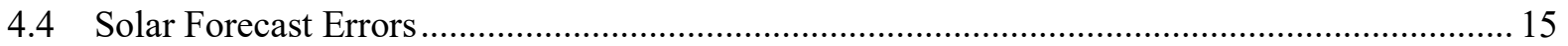

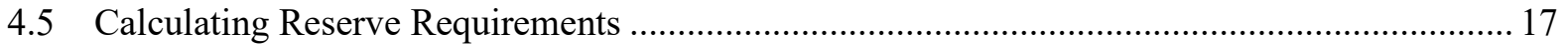

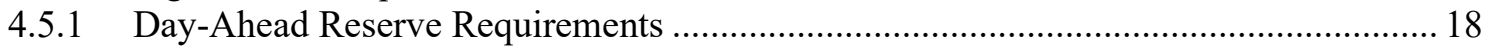

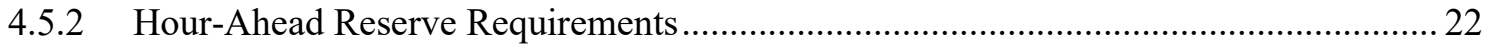

4.5.3 Sub-Hourly Reserve Requirements .................................................................... 24

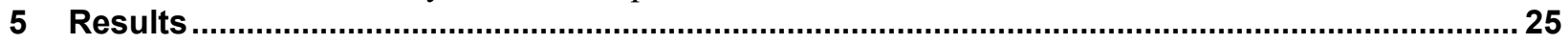

5.1 Current Reserve Requirements Depend on Balancing Authority Size and Operational Practices

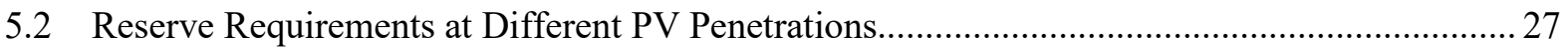

5.2.1 Mitigation Option 1: Increase Operational Frequency ............................................ 29

5.2.2 Mitigation Option 2: Coordinate Operations with Other Balancing Authorities ........... 29

5.3 Sensitivity to Accuracy of Day-Ahead Solar Forecast............................................................... 30

5.4 Sensitivity to Percent of Forecast Errors Covered ….............................................................. 31

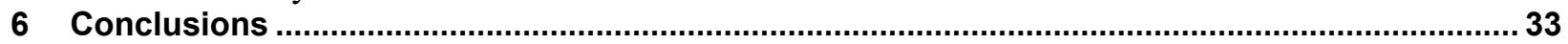

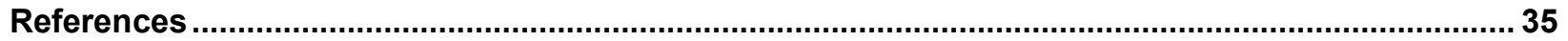

Appendix A. Time Synchronized Load and Solar Data Set Details ............................................. 40

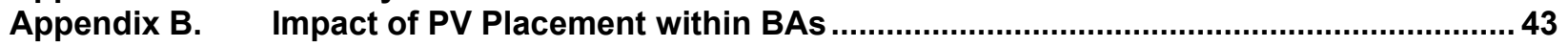




\section{List of Figures}

Figure 1. Geographic location and interconnections between FRCC BAs ...............................................2

Figure 2. Workflow used to construct time-synchronized load and solar data sets for FRCC balancing

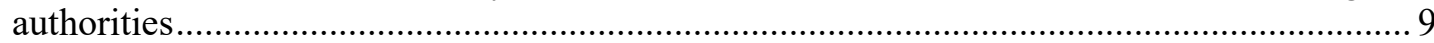

Figure 3. Example net-load shapes for different balancing authorities, seasons, and PV penetrations ...... 10

Figure 4. Clear-sky fraction ramp envelopes for eight BAs with similar amounts of simulated PV capacity (around $1 \mathrm{GW}$ )

Figure 5. Clear-sky fraction ramp envelopes for eight BAs with PV penetrations on an annual generation

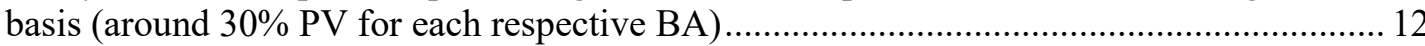

Figure 6. Historical day-ahead load forecast errors for FRCC balancing authorities as reported in EIA

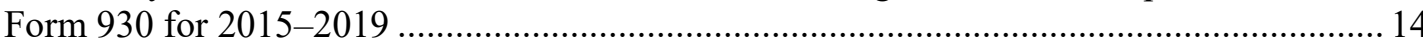

Figure 7. Hour-ahead load forecast made by persisting day-ahead forecast errors, illustrated for an

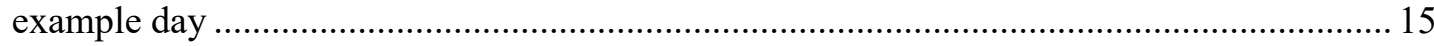

Figure 8. Example day-ahead solar forecast constructed using clear-sky persistence.............................. 16

Figure 9. Solar forecast error distributions as a fraction of PV capacity .............................................. 17

Figure 10. Illustration of the geometric sum of load and solar reserves .............................................. 18

Figure 11. Study process for estimating reserve requirements under assumed day-ahead operational

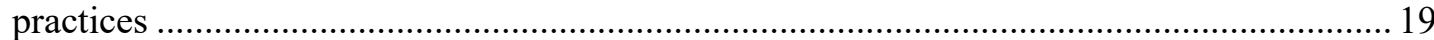

Figure 12. Municipal utility balancing reserve needs to cover day-ahead load forecast errors.................. 20

Figure 13. Example day-ahead solar reserve requirements based on day-ahead forecast errors, by clearsky ramp bin and for two levels of solar generation in TAL ............................................. 21

Figure 14. Example day-ahead solar reserve requirements based on $75 \%$ more accurate day-ahead forecast errors, by clear-sky ramp bin and for two levels of solar generation in TAL .......... 21

Figure 15. Study process for estimating reserve requirements under assumed hour-ahead operational

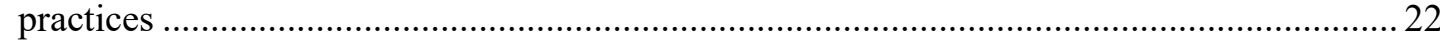

Figure 16. Municipal utility balancing reserve needs to cover hour-ahead load forecast errors ............... 23

Figure 17. Estimated reserve needs to cover $80 \%$ and $95 \%$ of TAL hour-ahead solar forecast errors with 584-MW PV (about 30\% of annual load), differentiated by up and down reserves .............. 24

Figure 18. Study process for estimating reserve requirements under assumed hour-ahead operational practices

Figure 19. Up reserves needed to provide regulation and flexibility services with current operational practices and at planned PV penetration levels (top panel: as a percentage of load in each timestep; bottom panel: in absolute megawatts)

Figure 20. Up reserves (top: as a percentage of load in each timestep; bottom: in megawatts) needed to provide regulation and flexibility services at current and future PV penetration levels ........ 28

Figure 21. Up reserves needed (as a percentage of load in each timestep) to provide regulation and flexibility services in GVL at current and future PV penetration levels with day-ahead or hourly operation

Figure 22. Up reserves needed (as a percentage of load in each timestep) to provide regulation and flexibility services under different PV penetration levels in GVL and MUNIS .

Figure 23. Up reserves needed (as a percentage of load in each timestep) in GVL using day-ahead operation with different day-ahead solar forecast accuracies at planned, 16\%, and 32\% PV penetration and covering $95 \%$ of load and solar forecast errors.....

Figure 24. Up reserves needed (as a percentage of load) in FPL with sub-hourly operation covering different percentages of forecast errors at current PV penetration...

Figure 25. Up reserves needed (as a percentage of load) in smaller BAs with hourly operation (top panel) and larger BAs with sub-hourly operation (bottom panel) covering different percentages of forecast errors under around $30 \% \mathrm{PV}$ penetration 


\section{List of Tables}

Table 1. FAASSTeR Core Team Members

Table 2. Summary of BAs Studied in this Analysis, with Estimates of PV Capacity and Annual Load for 2024

Table 3. Summary of FRCC Municipal BA Operating Practice............................................................. 6

Table 4. Scenario Framework for Studying the Impact of PV on Reserve Needs Depending on BA Size

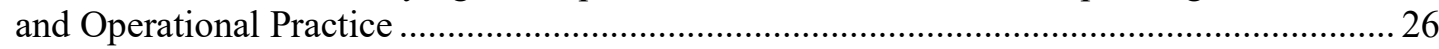

Table 5. Annual Net Energy for Load by BA, FERC Form 714, and Ten-Year Site Plans...................... 40

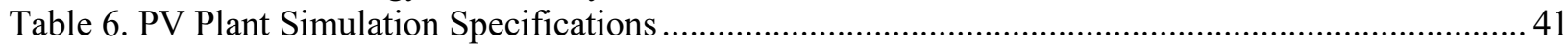

Table 7. Summary of Modeled BA Annual Load and PV Capacity for Annual PV Generation up to 50\% of Annual Load, in 10\% Increments 


\section{Introduction}

The Florida power system is composed of vertically integrated investor-owned utilities, municipal utilities, and co-ops. The State of Florida does not have a renewable portfolio standard, but as solar photovoltaic (PV) prices have declined, almost all Florida utilities have begun procuring solar capacity. Utility-scale solar reached 2,658 megawatts (MW) in 2020 (Florida Public Service Commission 2020). This trend is expected to continue as PV prices further decline (NREL 2020; Bolinger et al. 2020) and city-level renewable energy goals grow in number and stringency (City of Gainesville 2018; City of Tallahassee 2019; City of Orlando 2017). Over the next 10 years, the state anticipates $13,303 \mathrm{MW}$ of new solar PV capacity (Florida Public Service Commission 2020).

Numerous studies of renewable energy integration and the value of renewable energy forecasting suggest that Florida power system operators may modify their operations to absorb increasing amounts of solar generation. In addition to cycling generators and periodically curtailing solar to satisfy, e.g., minimum generation and ramp-rate limits (Hale, Stoll, and Novacheck 2018), Florida balancing authorities (BAs) may integrate solar forecasting (Martinez-Anido et al. 2016) and specify additional operating reserves to cover increasing net-load ${ }^{3}$ variability and uncertainty on 4-second (regulating reserve) to 1-hour (ramping) timescales (Ibanez et al. 2012; Ela et al. 2014).

These activities can be undertaken by power system operators of any size; however, the actions required of large system operators or neighboring systems operated cooperatively are smaller than those required of a small system when measured on a normalized basis (e.g., percent of load for a given solar penetration) due to the damping effects of aggregating many geographically dispersed solar plants (Mills and Wiser 2010; Parsons et al. 2014; van Haaren, Morjaria, and Fthenakis 2012). Although this fact is generally known, the impacts on reserve requirements have not been well quantified for small utilities. For example, Bloom et al. (2016) quantify the reserve savings of BA aggregation, but their smallest level of aggregation corresponds to our most aggregated case.

The Florida municipal utilities make a good case study in this regard, as they are operated as four different BAs of varying size. They can also be analyzed alongside other Florida Reliability Coordinating Council (FRCC) ${ }^{4}$ balancing authorities that add to the diversity of system size and ownership type (Figure 1). Table 2 summarizes the FRCC BAs as they were represented in our analysis, which began in 2018 and uses 2024 as its study year.

\footnotetext{
${ }^{3}$ Net load refers to load minus variable generation (e.g., from solar or wind plants). In other words, it is the amount of generation to be supplied from more dispatchable generators. In this paper, net load primarily refers to load minus solar generation.

${ }^{4}$ Starting from July 1, 2019, FRCC has been winding down its regional entity functions, but will continue its traditional member functions and coordinating roles, which include its work as a Reliability Coordinator and Planning Authority. SERC is the new Compliance Enforcement Authority for all North American Electric Reliability Corporation (NERC) registered entities that are currently within the FRCC Region (FRCC 2019). In 2019, early release of U.S. Energy Information Administration (EIA) Form 861 reported some utilities listed in Table 1 as SERC and others as FRCC. For consistency, we use 2018 data instead.
} 


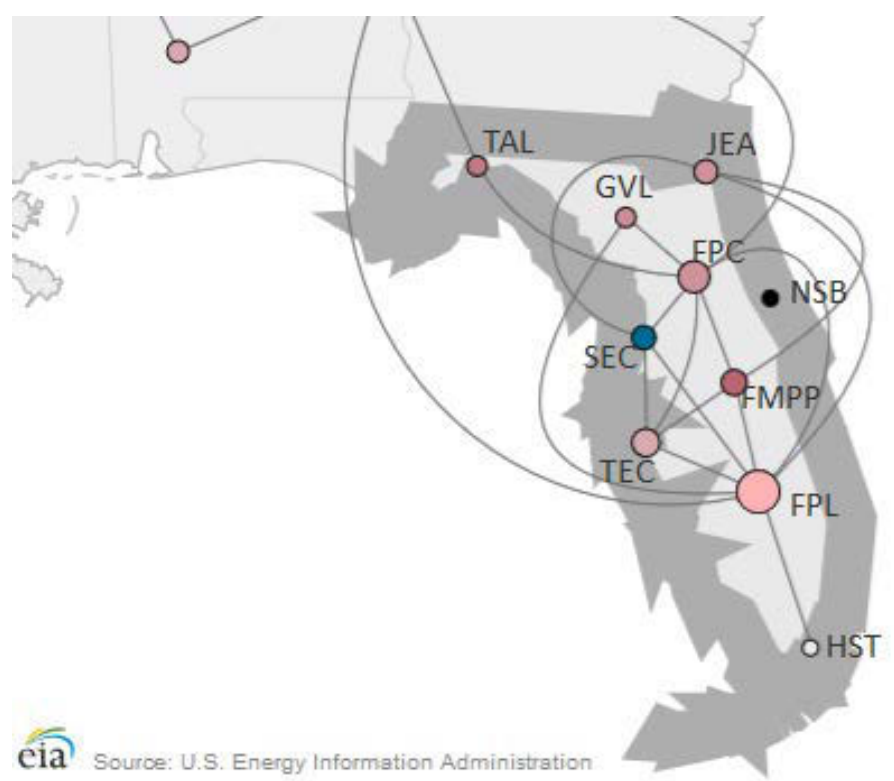

Figure 1. Geographic location and interconnections between FRCC BAs

Table 2. Summary of BAs Studied in this Analysis, with Estimates of PV Capacity and Annual Load for 2024

\begin{tabular}{|c|c|c|c|c|c|c|c|c|}
\hline BA ID & BA Name ${ }^{a}$ & $\begin{array}{c}\text { Ownership } \\
\text { Type }\end{array}$ & $\begin{array}{c}\text { Generation } \\
\text { Capacity } \\
(\mathrm{MW})^{\mathrm{b}, \mathrm{c}}\end{array}$ & $\begin{array}{c}\text { PV } \\
\text { Capacity } \\
(\mathrm{MW})^{\mathrm{b}, \mathrm{d}}\end{array}$ & $\begin{array}{c}\text { PV } \\
\text { Capacity } \\
(\%)\end{array}$ & $\begin{array}{c}\text { Annual } \\
\text { Loadd,e } \\
\text { (TWh) }\end{array}$ & $\begin{array}{c}\text { Annual PV } \\
\text { Generation } \\
\text { (GWh) }\end{array}$ & $\begin{array}{c}\text { PV } \\
\text { Generation } \\
(\%)\end{array}$ \\
\hline GVL & $\begin{array}{l}\text { Gainesville } \\
\text { Regional } \\
\text { Utilities }\end{array}$ & Municipal & 750 & 1.2 & 0.2 & 1.73 & 1.8 & 0.1 \\
\hline TAL & $\begin{array}{l}\text { City of } \\
\text { Tallahassee } \\
\text { Utilities }\end{array}$ & Municipal & 1,009 & 60.0 & 5.9 & 2.93 & 88.1 & 3.0 \\
\hline JEA & JEA & Municipal & 2,555 & 277.4 & 10.8 & 14.09 & 422.1 & 3.0 \\
\hline SEC & $\begin{array}{l}\text { Seminole } \\
\text { Electric } \\
\text { Cooperative }\end{array}$ & Cooperative & 4,141 & 2.2 & 0.1 & 15.79 & 4.0 & 0.0 \\
\hline FMPP & $\begin{array}{l}\text { Florida } \\
\text { Municipal } \\
\text { Power Pool }\end{array}$ & Municipal & 5,640 & 244.4 & 4.3 & 16.07 & 374.9 & 2.3 \\
\hline TEC & $\begin{array}{l}\text { Tampa } \\
\text { Electric } \\
\text { Company }\end{array}$ & $\begin{array}{l}\text { Investor } \\
\text { Owned }\end{array}$ & 7,783 & 626.7 & 8.0 & 21.51 & $1,016.2$ & 4.7 \\
\hline FPC & $\begin{array}{l}\text { Duke Energy } \\
\text { Florida, Inc. }\end{array}$ & $\begin{array}{l}\text { Investor } \\
\text { Owned }\end{array}$ & 13,175 & 304.0 & 2.3 & 43.32 & 487.0 & 1.1 \\
\hline FPL & $\begin{array}{l}\text { Florida } \\
\text { Power \& } \\
\text { Light } \\
\text { Company }\end{array}$ & $\begin{array}{l}\text { Investor } \\
\text { Owned }\end{array}$ & 30,915 & $1,007.0$ & 3.2 & 123.30 & $1,645.8$ & 1.3 \\
\hline
\end{tabular}

a 2018 EIA Form 861 data (EIA 2019)

${ }^{\mathrm{b}}$ Nameplate capacity of current generators, planned builds, and retirements as represented in the SNL database (S\&P Global 2018) as of October 2018, plus known planned PV builds in JEA and FMPP 
${ }^{\mathrm{C}}$ In some cases, distributed generators/co-gen units are included and assigned to the hosting BA (thus overstating BA-level generating capacity)

d Distributed PV capacity is not included. Consistent with that, annual load is the "net energy for load," which does not include load that is served by behind-the-meter generation.

e Estimated annual load for 2024, created by combining Federal Energy Regulatory Commission (FERC) Form 714 net energy for load 2006-2015 (FERC 2015) and net energy for load growth rates from the 2019 Florida electric utilities' Ten-Year Site Plans (Florida Public Service Commission 2019). Further details are provided in Section 4.1.

This analysis benefited from close cooperation with Gainesville Regional Utilities (GRU or GVL), the City of Tallahassee Electric \& Gas Utility (TAL), JEA (Jacksonville's municipal utility), Orlando Utilities Commission (OUC), Lakeland Electric, and the Florida Municipal Electric Association (FMEA) through the Florida Alliance for Accelerating Solar and Storage Technology Readiness (FAASSTeR) project. ${ }^{5}$ Iterating with team members and visiting during workshops helped the authors better understand how GVL, TAL, JEA, and the Florida Municipal Power Pool (FMPP) - the latter of which jointly operates FMEA, OUC, and Lakeland Electric resources - operate today, and what challenges they may have integrating more PV generation in the near term.

This paper describes the impact of system size and operating practice on the amount of balancing reserves that need to be held to cover the variability and uncertainty of net load over a wide range of PV penetrations. By performing this study in the context of FRCC and the municipal utilities therein, we aim to provide specific information of use to those utilities and the State of Florida more broadly, as well as general information of interest to the power system community.

\section{Large System Operational Practices and Implications for Balancing Reserves}

Power systems are operated with an interlocking series of processes, each of which is characterized by its key decisions and time frames. Focusing on the day-to-day operations that ensure electricity supply and demand balance at all times, these processes can generally be categorized into the three stages of unit commitment (UC), security-constrained economic dispatch (SCED), and real-time operations. The first stage is typically run once a day, ahead of the following day's operations, and is therefore often referred to as day-ahead UC. In the UC process, the system operator determines the least-cost combination of generating units to be on during each time interval in the next 24-hour period based on the day-ahead load forecast and respecting the limitations of the transmission system and each unit's physical operating constraints, including minimum off and on times (FERC 2006). This process fixes the binary on/off unit commitment decision for slower-starting generators (e.g., nuclear, coal, and natural gas combined cycle plants) and provides an initial dispatch plan that is refined in subsequent stages.

The second stage, SCED, happens throughout the operating day, on regular, potentially interlocking schedules, or in response to new information. During SCED, operators determine the level at which each committed resource should operate to ensure reliability at minimum cost, subject to the physical, contractual, and institutional constraints in the system. In addition to the units committed in the first stage, operators can also quick-start generators (e.g., natural gas combustion turbines) on reserve to respond to unexpected changes in supply and demand or contingencies (Milligan et al. 2012). Real-time operations must keep the demand, generation,

${ }^{5}$ https://faasster.org/ 
and interchange in balance to maintain a system frequency within defined limits (NERC 2016). During real-time operations, generators follow the dispatch plans set by the SCED phase; for a subset of generators, those plans include the supply of operating reserves, which are the control mechanisms by which real-time balancing and reliability are achieved.

Operating the power system is difficult because there is variability and uncertainty in both supply and demand, and the two must be in balance every second. Operating reserves are needed to achieve this feat for both normal operation and during severe, yet rare, events (Ibanez, Krad, and Ela 2014). Among the operating reserves, regulation is held to provide continuous, fast, and frequent (second-to-second and minute-to-minute) correction of supply and demand and provide frequency support (NERC 2017). The service is dispatched by system operators sending out a 4second-interval automatic generation control (AGC) signal to generating units and responsive loads that have the ability to rapidly adjust their dispatch set point and automatically follow such signals. This regulation process is a key part of operators' balancing strategies during normal operation (Ela, Milligan, and Kirby 2011). Flexibility reserve, also known as ramping reserve, is used to respond to less frequent failures and events that occur over longer time frames (typically 10-20 minutes) and that may lead to a shortage of ramping capability, such as wind forecast errors (Milligan et al. 2010). Regulating reserve is required in all U.S. power markets, whereas ramping reserve is an emerging product that is currently only available in the California Independent System Operator (CAISO) and Midcontinent Independent System Operator (MISO). In this report, we use balancing reserves to refer to these two types of real-time adjustments that operate at different timescales.

NERC requires BAs to hold sufficient amounts of operating reserves to respond to imbalances between demand and supply, recover after an event (e.g., sudden loss of supply or transmission), and respond to frequency deviations, but leaves the specific calculation of the reserve needs to the balancing area's discretion (NERC 2002). Failure to meet a frequency-related control performance standard or exceeding the balancing authority area control error limit for more than 30 consecutive minutes triggers a violation (NERC 2016) and results in a base penalty that ranges from $\$ 1,000-\$ 25,000 /$ day and $\$ 2,000-\$ 335,000 /$ day, depending on such factors as violation risk factor, severity level, and the BA's compliance history (NERC 2014). The addition of solar PV increases the variability and uncertainty between day-ahead scheduling and real-time operations (Shedd et al. 2012; Lew et al. 2013). As a result, additional regulation and flexibility reserves may be deployed to stay within NERC's reliability bounds by managing the added variability and uncertainty (CAISO 2010; Mills et al. 2013; Lu et al. 2011; Ma et al. 2012).

Newer flexibility (or ramping) reserve products have been designed to address deviations from the forecasted net-load ramp. As such, they are generally slower (i.e., lower ramp rate) and longer in duration than regulating reserves. For example, CAISO procures flexible ramping reserve (both up and down in the 15-minute and 5-minute markets) at a maximum of the $2.5^{\text {th }}$ percentile (down reserves) and the $97.5^{\text {th }}$ percentile (up reserves) of the net-load error (Westendorf 2018). It is continuously procured and dispatched in the real time dispatch. This ensures that sufficient ramp capability is committed in the real-time unit commitment to cover uncertainty materializing in real-time dispatch, but does not cover uncertainty between the 15minute market runs (CAISO 2020). A variety of technologies provide this service, including natural gas, hydro, demand response, and coal. The price of flexible ramping reserve is very low in the upward direction and almost always at \$0 per megawatt-hour (MWh) in the downward direction (CAISO 2020). In contrast, regulation reserves are dispatched after the final SCED run 
(sometimes referred to as the real-time market), through following the AGC signal, not through economic bids, because the system relies on regulation reserves to resolve second-to-second imbalances that drive frequency deviation and area control error (CAISO 2015). CAISO's regulation reserve averaged around $430 \mathrm{MW}$ and $350 \mathrm{MW}$ (representing $1.0 \%$ and $0.8 \%$ of peak load) for up and down regulation in 2019, respectively, and typically has the highest price among all ancillary services (CAISO 2020). It is served primarily by natural gas and hydro, with an increasing share served by battery storage.

Capacity expansion models (CEMs), which are used in planning processes to help determine what new generating units may be needed and what older generating units should be retired, often include reduced-form representations of reserve requirements to ensure that they are planning a realistic, reliable system. The CEMs that the authors are familiar with were designed for larger systems with significant quantities of wind and solar generation, and therefore have reserve requirements that attempt to summarize the reserve needs implied by different quantities of wind and solar capacity (Halamay et al. 2011; Sullivan, Eurek, and Margolis 2014). For example, the National Renewable Energy Laboratory's (NREL's) Regional Energy Deployment System (ReEDS) capacity expansion model (Brown et al. 2020) requires regulation reserve to be $1 \%$ of load plus $0.5 \%$ of wind generation and $0.3 \%$ of solar PV capacity, and flexibility reserves equal to $10 \%$ of wind generation plus $4 \%$ of solar PV capacity, with the additional reserves for PV only held during daylight hours. These requirements were derived from Ibanez et al. (2012) and are generally understood to apply only to large-enough BAs operating with day-ahead unit commitment followed by intraday and sub-hourly (SH) SCED, with all operations informed by load, wind, and solar forecasts at the relevant timescales.

\section{Florida Municipal Utilities' Operational Practices}

In Florida, 33 municipal electric utilities serve approximately three million residents $-14 \%$ of the state's population (FMEA 2020). Their operational practices in forecasting, dispatch, and reserves vary. To understand their practices, we sent a questionnaire out to six utilities: GVL, TAL, JEA (formerly Jacksonville Electric Authority), Lakeland Electric, Florida Municipal Power Agency (FMPA), and OUC.

The questionnaire focused on four issues: (1) operational relationships, including trading and reserve sharing partners; (2) dispatch and reserve practices, including unit commitment frequency, dispatch frequency, software, reserve amount, risks, and concerns; (3) load forecasting, including historical data used, forecast method, forecast scope, accuracy, and corrective actions; and (4) solar forecasting, including method and scope.

One of our main observations based on the questionnaire answers is that the municipal BAs have significantly different forecast and dispatch procedures (Table 3). GVL, for example, relies mainly on day-ahead forecasting, unit commitment, and dispatch. Because they dispatch only a handful of generating units, the headroom of the one or two units assigned to follow the AGC signal is relatively large proportional to load such that GVL can ride through most day-ahead forecast errors using the day-ahead dispatch plan — additional forecast adjustments mid-day would be unlikely to significantly change dispatch instructions. TAL and JEA are the only BAs in this group that systematically update load forecasts and system dispatch on an hourly basis. FMPP is the only BA to incorporate solar forecasts based on expected weather. At this point, 
none of the Florida municipal utilities are conducting sub-hourly, real-time dispatch with accompanying sub-hourly load and solar forecasts.

Table 3. Summary of FRCC Municipal BA Operating Practice

\begin{tabular}{|c|c|c|c|c|c|}
\hline \multirow{2}{*}{$\begin{array}{l}\text { Balancing } \\
\text { Authority }\end{array}$} & \multicolumn{2}{|c|}{ Day-Ahead Forecasting } & \multicolumn{2}{|l|}{ Intraday Updates } & \multirow{2}{*}{$\begin{array}{l}\text { Operating } \\
\text { Reserves }\end{array}$} \\
\hline & Load & Solar & Load & Solar & \\
\hline $\begin{array}{l}\text { Gainesville } \\
\text { (GVL) }\end{array}$ & $\begin{array}{l}\text { Hourly } \\
10-d a y \\
\text { horizon }\end{array}$ & $\mathrm{N} / \mathrm{A}$ & $\mathrm{N} / \mathrm{A}$ & $\mathrm{N} / \mathrm{A}$ & $N / A^{b}$ \\
\hline $\begin{array}{l}\text { Tallahassee } \\
\text { (TAL) }\end{array}$ & $\begin{array}{l}\text { Hourly } \\
\text { 16-day } \\
\text { horizon }\end{array}$ & $\begin{array}{l}\text { Hourly } \\
\text { fixed profile }\end{array}$ & Hourly updates & N/A & $\pm 16 \mathrm{MW}$ \\
\hline JEA & $\begin{array}{l}\text { Hourly } \\
\text { 14-day } \\
\text { horizon }\end{array}$ & $\mathrm{N} / \mathrm{A}$ & $\begin{array}{l}\text { Hourly } \\
\text { 5-min updates }\end{array}$ & N/A & $\pm 50 \mathrm{MW}$ \\
\hline $\begin{array}{l}\text { FMPP (incl. } \\
\text { FMPA, OUC, } \\
\text { Lakeland) }\end{array}$ & $\begin{array}{l}\text { Hourly } \\
\text { 7-day horizon }\end{array}$ & $\begin{array}{l}\text { Hourly } \\
\text { 7-day horizon }\end{array}$ & $\begin{array}{l}\text { Infrequent updates } \\
\text { as needed }\end{array}$ & $\begin{array}{l}\text { Infrequent updates } \\
\text { as needed }\end{array}$ & $\begin{array}{l}+50 \mathrm{MW}^{\mathrm{a}, \mathrm{b}} \text { (more } \\
\text { if no quick starts) }\end{array}$ \\
\hline
\end{tabular}

a FMPP requires $50 \mathrm{MW}$ of up reserve during unit commitment, primarily to have sufficient spinning capacity to meet Florida Reserve Sharing Group obligations. As such, this does not represent "regulation reserves" per se.

${ }^{b}$ Although Gainesville and FMPP do not have precise regulation reserve requirements, during real-time operations they have significant capacity following AGC and continuously monitor both area control error and their ability to meet Florida Reserve Sharing Group obligations.

The findings from this questionnaire clarified that in addition to BA size, it is important to consider operational practice as a key driver that impacts the amount of reserves a BA needs to hold to manage net-load variability and uncertainty. We identified three categories of operational practice, distinguished by the highest frequency of forecasts and dispatch: day-ahead (only), hour-ahead, and sub-hourly. This process also clarified that the reserves literature for systems with significant wind and solar generation, which almost exclusively addresses these questions for large BAs with sub-hourly operations, provides little actionable information for smaller BAs with less frequent dispatch.

\section{Methods}

The amount of reserves a balancing authority needs to hold fundamentally depends on the expected sizes of the gaps between generator dispatch points and actual demand. For balancing (e.g., regulation and flexibility) reserves, the key differences of interest are between forecasted and actual demand, because under normal operating conditions the system dispatch will be set to follow the load forecast - reserves then need to be available to make up the difference between the forecasted dispatch point and the actual real-time demand. Because PV generation is zero marginal cost, its variable output is generally dispatched first and, in many ways, shows up in the system as a negative load. Therefore, we can also think about balancing reserves in relation to the gap between forecasted and actual net load, where for the purposes of this study net load is 
defined as load minus PV generation. ${ }^{6}$ In either case, balancing reserve requirements are driven by forecast errors.

Although we are ultimately interested in net-load forecast errors, because load and solar data are fundamentally different, in this study we estimate load and solar forecast errors separately, estimate the amount of reserves needed to cover those types of forecast errors separately, and then combine them (nonlinearly) to arrive at an overall reserves requirement.

We focus on estimating reserve requirements for different FRCC BAs assuming different levels of PV penetration and different operating practices. We estimate forecast errors for load and solar generation using different forecasting horizons (e.g., day-ahead, hour-ahead, or 5-minuteahead), selected based on assumed operational practice. The forecast methods we use are conservative, persistence-type forecasts that have low data requirements but are tailored to make use of all the load and solar data that were available. Then, the estimated load or solar forecast errors are binned and we compute percentile levels per bin to establish a per-bin level of reserves in megawatts or percent of load. The reserve requirements are then applied to a timesynchronized data set of historical load and simulated solar generation that covers 2007-2012 at 5-minute resolution (described in the next subsection and in Appendix A). Our results consist of statistical summaries of the reserve requirements themselves, which we use to analyze the impact of PV generation and operational practices on the reserve requirements of FRCC BAs of different electrical size and geographic extent.

\subsection{Time-Synchronized Load and Solar Data Sets}

The primary inputs of our analysis are historical load shapes paired with solar generation profiles created to contain an amount of available energy approximately equal to a certain percentage of annual load. The simulated solar generation profiles are for the same weather years as the historic load shapes to capture realistic correlations between load and solar generation. Our starting point for analysis is an estimate of PV capacity and annual load levels for the 2024-time frame.

The load profiles used in our analysis are historical data from 2007-2012 that were scaled to contain an equal amount of load in each year. The original data are 2006-2015 net energy for load for the eight BAs listed in Table 2. The energy contained in each profile was scaled to capture the growth expected between 2015 and 2024 by the 2019 Florida electric utilities' TenYear Site Plans (Florida Public Service Commission 2019). We chose 2024 as the target model year to better align with our starting point of all planned PV capacity (current plants plus known PV development plans).

The goal of the study was to analyze reserve requirements over a wide range of solar penetrations, where solar penetration is defined as the percent of annual load that, on net and absent any solar curtailment, could be supplied by solar generation. To develop realistic solar generation profiles for each BA, we started with the locations of existing and planned PV plants

\footnotetext{
${ }^{6}$ More generally, net load is defined as load minus all variable generation, which could include resources like wind and run-of-river hydro, in addition to PV.
} 
and then added simulated PV plants to obtain aggregate generation profiles with realistic geographic scaling.

Solar profiles for 2007-2012 are available on a location-by-location basis from the Renewable Resource and Power Data tool (R2PD). ${ }^{7}$ R2PD is a python interface for pulling Wind Integration National Dataset (WIND) Toolkit and Solar Integration National Dataset (SIND) Toolkit data from the DR POWER repository ${ }^{8}$ to produce aggregate, power system modeler-friendly wind, solar, and weather profiles. The actual and clear-sky solar generation profiles were originally computed using the System Advisor Model (SAM) (Blair et al. 2018) and basic specifications for utility-scale fixed-tilt and one-axis tracking plants, the former for urban and the latter for rural sites. Clear-sky generation is simulated based solely on latitude, longitude, date and time information, and plant specifications - it is the electricity output that would be expected if every day were perfectly sunny, which is a useful benchmark for understanding how actual generation compares to its theoretical maximum. Actual generation for historical conditions is simulated with the System Advisor Model using data from the National Solar Radiation Database (NSRDB) downscaled from 30- to 5-minute resolution using the methods described in Buster et al. (2021).

Solar generation is placed near BAs' transmission nodes, using a database, GridDB, that identifies which nodes are associated with each BA and which nodes are associated with existing or planned PV plants, existing or planned generation of any type, upcoming generation retirements, or load. Specific PV expansion sites were then selected by specifying which types of nodes were candidates for placement, and what percentage should be randomly selected for inclusion. As described in Appendix B, although there were many options for determining PV expansion nodes, this ended up having negligible impact on our results. In what follows, all results were produced by randomly selecting 50\% of a BA's nodes for PV expansion.

${ }^{7}$ https://github.com/Smart-DS/R2PD

${ }^{8}$ https://egriddata.org/dataset/nrel-renewable-energy-resource-data 
Solar Scenario

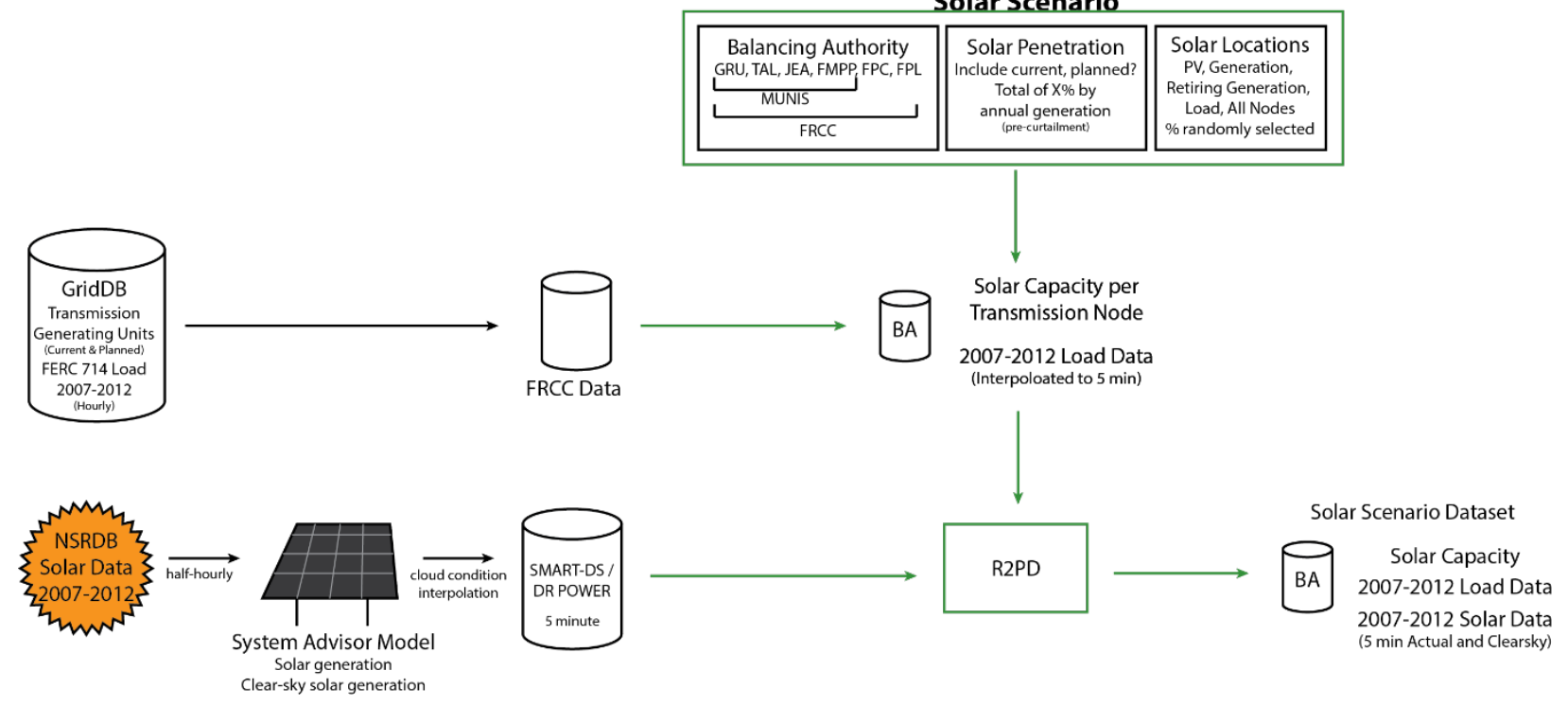

Figure 2. Workflow used to construct time-synchronized load and solar data sets for FRCC balancing authorities

The workflow for creating per-balancing authority data sets of load and solar data is shown in Figure 2. Once the balancing authority, solar penetration, and solar expansion locations are specified, R2PD requires a list of specific PV capacities (in megawatts) to place at specific latitude-longitude locations. If current and/or planned PV capacity is to be included, that capacity is placed first and it is noted what percent of annual load that amount of generation covers. (For example, Tallahassee's current and planned PV capacity is $60 \mathrm{MW}$, which in our data set corresponds to $3 \%$ of annual load.) Then, if additional PV capacity is desired (e.g., if we want a $20 \%$ PV scenario for Tallahassee), we do a test run by placing $1 \mathrm{MW}$ of capacity at each selected $\mathrm{PV}$-expansion node, getting the resulting profiles, and then stating the amount of generation in units of percent of annual load per megawatt placed at all selected nodes (e.g., for our main Tallahassee case, we found $1.08 \%$ annual load per megawatt placed at 21 selected PV-expansion nodes). That factor is then used to determine how many megawatts per PV-expansion node should be placed to reach the target penetration (e.g., 15.8 MW for our running example to reach $20 \%$ PV, because $[20-3.0] / 1.08=15.8 \mathrm{MW}$ ). Finally, we have the information needed to run through the entire Figure 2 workflow. Because R2PD uses a nearest-neighbor search with no double counting of sites, the actual solar profiles that are output do not exactly match our desired levels of PV generation (e.g., our running example ended up with $21.0 \% \mathrm{PV}$ ). 

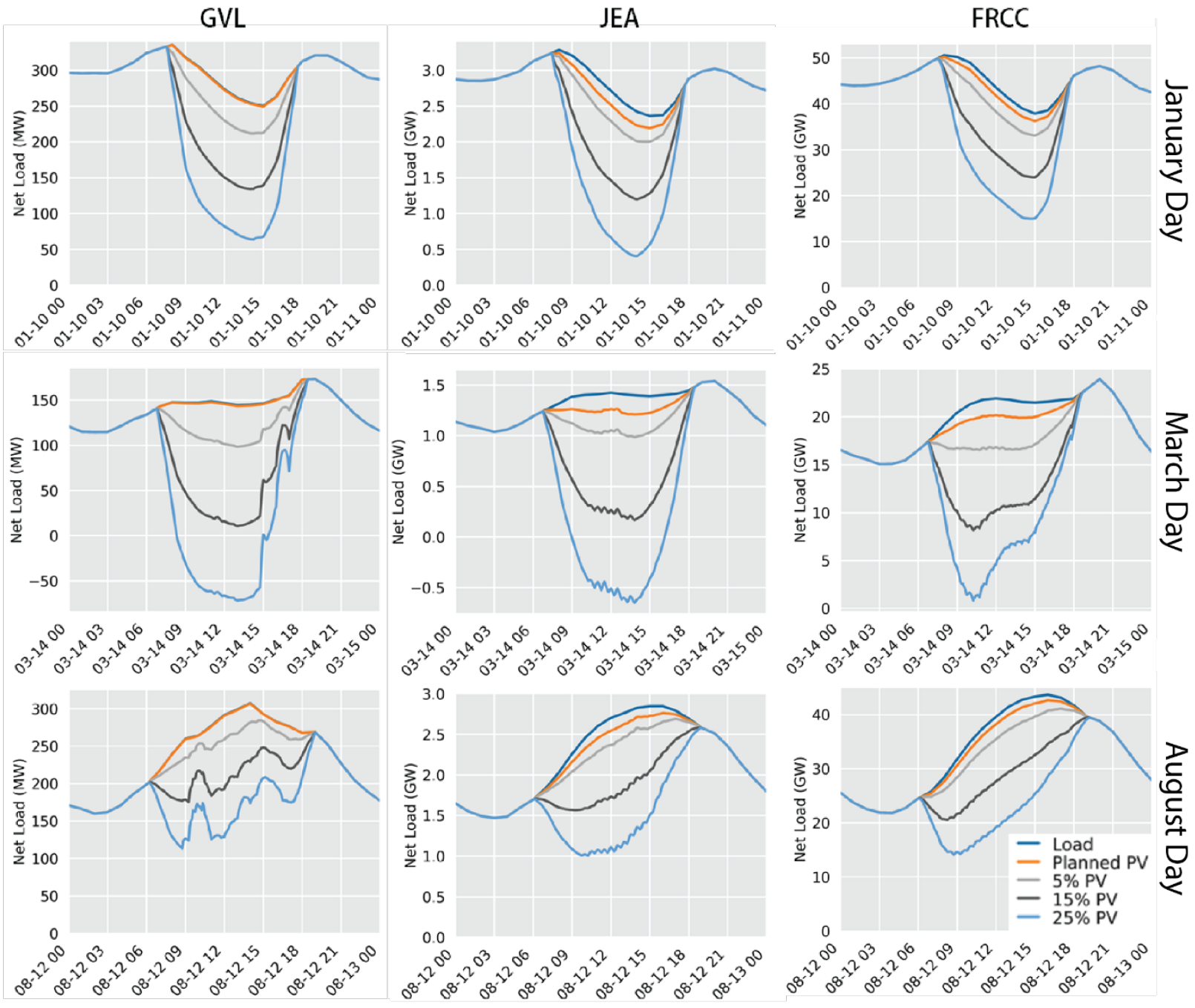

Figure 3. Example net-load shapes for different balancing authorities, seasons, and PV penetrations

The resulting data sets show expected net-load patterns that reflect balancing authority size, geographic distribution, seasonality, weather, and amount of solar generation. For example, Figure 3 shows how net-load patterns change with increasing amounts of PV for three selected historical days (one in January, one in March, and one in August) and balancing authorities of different sizes. For all three balancing authorities, we see similar seasonal load patterns: two daily peaks in winter that reflect significant amounts of electric heating, low and fairly flat daytime load with an evening residential peak in spring, and a classic summer-peaking pattern in August. Regarding solar generation, for similar penetration levels we see more variability in the net-load profiles of the smallest balancing authority (GVL) and much larger net-load dips on this particular March day in both GVL and JEA as compared to all of FRCC considered together. However, that does not mean that FRCC's profiles are unimpacted by weather; the March FRCC profile is influenced by widespread afternoon cloudiness, at least at higher PV penetrations. 


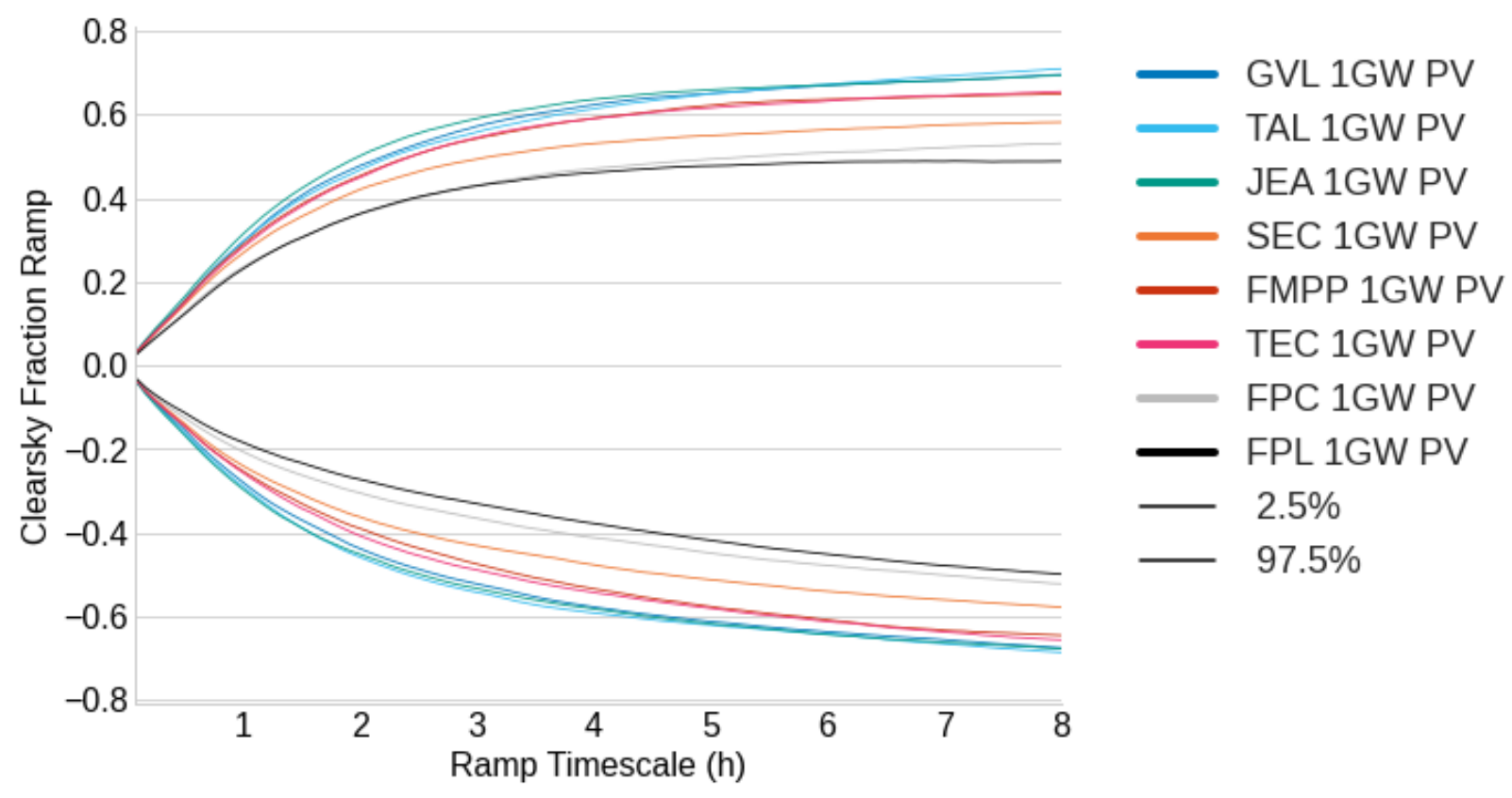

Figure 4. Clear-sky fraction ramp envelopes for eight BAs with similar amounts of simulated PV capacity (around $1 \mathrm{GW}$ )

The variability differences we see between smaller and larger BAs in individual daily profiles can be confirmed by summarizing larger quantities of data. Figure 4 and Figure 5 depict envelopes that contain $95 \%$ of the clear-sky fraction ramps $\left(R_{C F, \Delta t}\right)$, defined for each ramp timescale $\Delta t$ from 5 minutes to 8 hours as:

$$
R_{C F, \Delta t}(t)=C F(t)-C F(t-\Delta t)=\frac{G_{\text {actual }}(t)}{G_{\text {clearsky }}(t)}-\frac{G_{\text {actual }}(t-\Delta t)}{G_{\text {clearsky }}(t-\Delta t)}
$$

where $C F$ indicates clear-sky fraction, $G_{\text {actual }}$ is actual solar generation, and $G_{\text {clearsky }}$ is the corresponding solar generation under clear-sky conditions. The clear-sky fraction, $C F=G_{\text {actual }} / G_{\text {clearsky }}$, is an important quantity that describes how actual solar generation deviates from what would be expected under perfect conditions. Because it is normalized, it is also comparable across systems of any size. By plotting bounds that contain $95 \%$ of clear-sky ramps, the envelopes in Figure 4 and Figure 5 describe solar variability beyond what is already expected based on Earth's movements relative to the sun - the wider the envelope, the more variable the solar generation contained in the overall data set.

The envelopes in Figure 4 represent how the solar variability for the eight BAs differs with PV capacity fixed at around $1 \mathrm{GW}$. It therefore captures the impact of geographic area and dispersion. GVL, TAL, and JEA are all highly concentrated-they serve single cities, JEA being the largest - and their aggregate solar profiles therefore show the most variability, with highly correlated and thus reinforcing weather in the component profiles. TEC (serving much of the Tampa metropolitan area) and FMPP (with most load and transmission nodes concentrated between Orlando and the City of Lakeland) are both larger but still geographically concentrated, at least as compared to SEC, FPC, and FPL. As the largest BAs in FRCC by both system size and footprint, FPC and FPL not surprisingly show the greatest amounts of geographic averaging. 
SEC's positioning in this plot reflects the fact that it has a wide-ranging service territory covering much of rural Florida.

The differences in variability are even more pronounced if we look at similar PV penetration, measured here and in the remainder of the report as available PV generation ${ }^{9}$ divided by total energy demand, instead of similar PV capacity. Figure 5 shows clear-sky fraction ramps for eight BAs, all at around $30 \%$ PV penetration. Because the sizes of the BAs are so different, the corresponding capacities vary greatly - from GVL's $341 \mathrm{MW}$ to FPL's 23,400 MW-and we end up with clear groupings solely based on BA electrical (rather than geographic) size. Smaller quantities of PV show higher relative variability, such that GVL and TAL profiles are most variable, and FPL profiles are the least variable, according to the clear-sky fraction ramp metric.

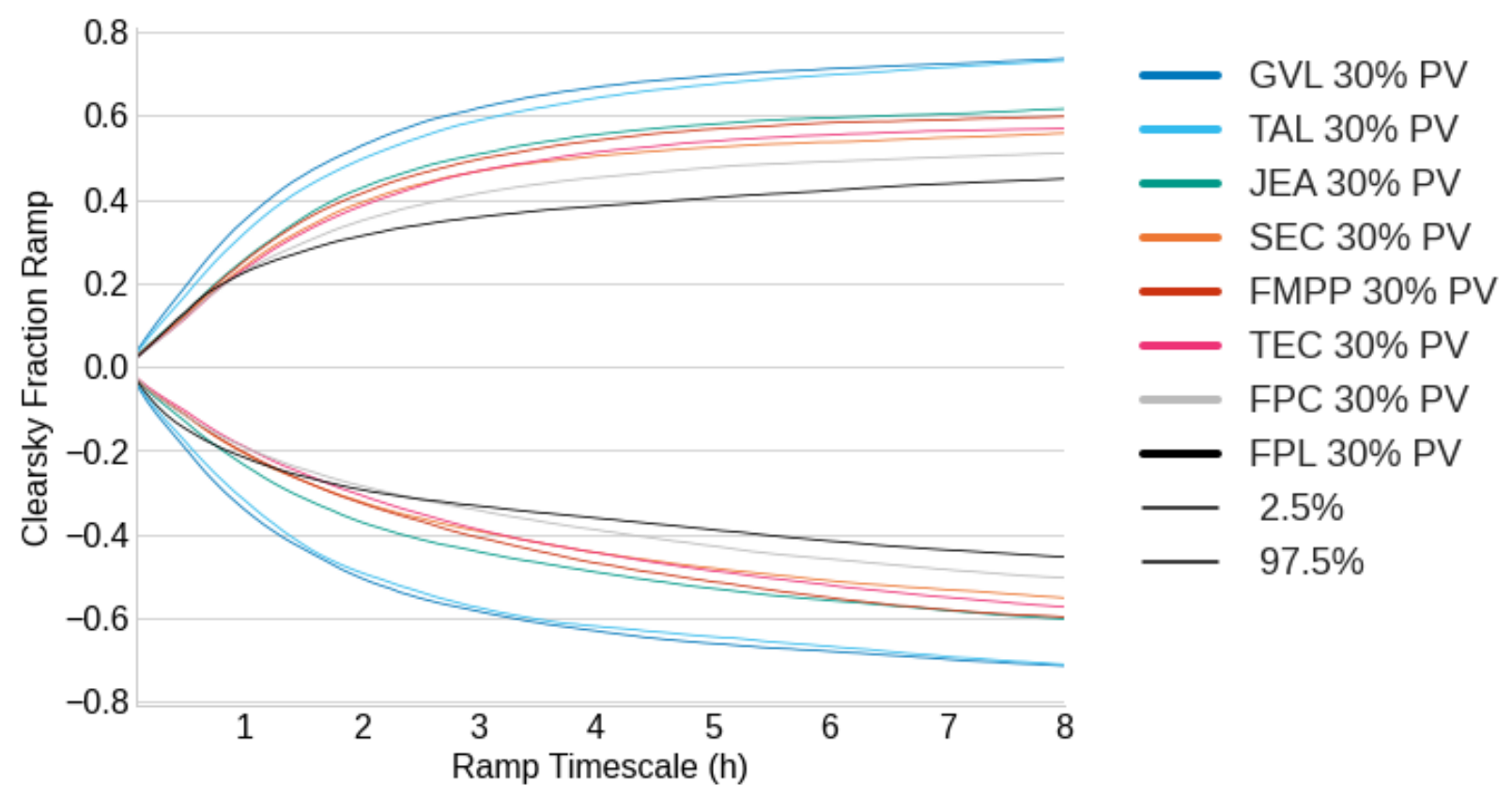

Figure 5. Clear-sky fraction ramp envelopes for eight BAs with PV penetrations on an annual generation basis (around $30 \%$ PV for each respective BA)

\subsection{Assumed Operational Practices}

Based on our understanding of Florida municipal utility and large balancing authority operations, we estimate balancing reserve requirements for three types of operational practice:

- Day-ahead (DA) forecasts and dispatch

- Hour-ahead (HA) forecasts and dispatch

- Sub-hourly (SH) forecasts and dispatch.

A utility that follows DA operational practice is assumed to create or obtain day-ahead load and solar forecasts, run a unit-commitment and SCED process to create an operational plan for the next day, and then typically use that plan as-is for the following day. By necessity, such

\footnotetext{
${ }^{9}$ Available PV generation refers to all potential PV generation from a set of PV plants, prior to any possible dispatch instructions that would have the plant deviate from full output (e.g., to curtail or provide reserves for reliability reasons).
} 
operations require commitment of a significant amount of capacity to follow an AGC signal and thereby keep area control error within NERC limits, because AGC will need to make up for dayahead forecast errors. Our example for this type of operation is Gainesville, which serves most of its load by dispatching just four main plants - a biomass steam turbine, a natural gas combined cycle plant, a natural gas combustion turbine plant, and a steam plant with one natural gas and one coal unit. Assigning the headroom that remains on one or two of these units to follow AGC gives the system plenty of balancing capacity as a percent of load.

HA operational practice starts with a day-ahead forecast and unit commitment and dispatch process, but during the following day, although the initial plan is set, the remainder of the day's plan is adjusted every hour as updated load and solar forecasts come in. In this case, balancing reserves only need to handle the difference between hour-ahead forecasts and actual net load, rather than the full day-ahead mismatch, and that amount of reserve requirement may be accounted for in both the day-ahead UC and the SCED processes, if reserves provision is cooptimized along with dispatch. Tallahassee and JEA are current exemplars of this type of operational practice, although currently only with respect to load forecasts. (Weather-based solar forecasts have not yet been incorporated into their operational practices.)

Large balancing authorities with SH operational practice typically go through day-ahead and hour-ahead steps (although the latter may be on a longer timescale, as many as 4 hours), but then also run a forecast and dispatch process at the 15- to 5-minute timescale. Regulation reserves therefore need to balance out second-to-second supply and demand differences whose sizes are dictated by 5 - to 15 -minute net-load forecast errors and variability. Flexibility reserves are procured at the 15-60-minute timescale and dispatched every 5 minutes to address any ramping challenges that emerge from variable generation forecasting errors. For simplicity of comparison with the other operational practice categories, we combine these two reserve types in our results. However, as discussed in Section 2, regulation reserve is generally the more demanding and expensive service.

\subsection{Load Forecast Errors}

Because the historical load data used in our 2007-2012 data set do not contain any information on load forecast errors, we need a different data source to estimate FRCC balancing authority load forecast errors. Fortunately, EIA Form 930 has been collecting hourly data, including dayahead forecast and actual load, from the balancing authorities since 2015. We therefore use this source of self-reported, historical day-ahead forecast error data, accessed via the ABB data service Energy Velocity Suite (2020), to directly quantify the uncertainty FRCC balancing authorities start with considering their day-ahead load forecast errors.

Figure 6 summarizes the historical day-ahead load forecast errors as reported in the EIA 930 data set. Different balancing authorities show significantly different levels of accuracy and distributional patterns. The data from SEC appear to contain many outliers that may signify frequent reporting errors. None of the BAs demonstrate classic normal distributions. Some of the balancing authorities' forecasts appear to be significantly biased-FPC's data are particularly notable in this regard as actual demand is usually significantly higher than forecast demand. The long negative tails may reflect hurricanes and other events that drive significant outages. 

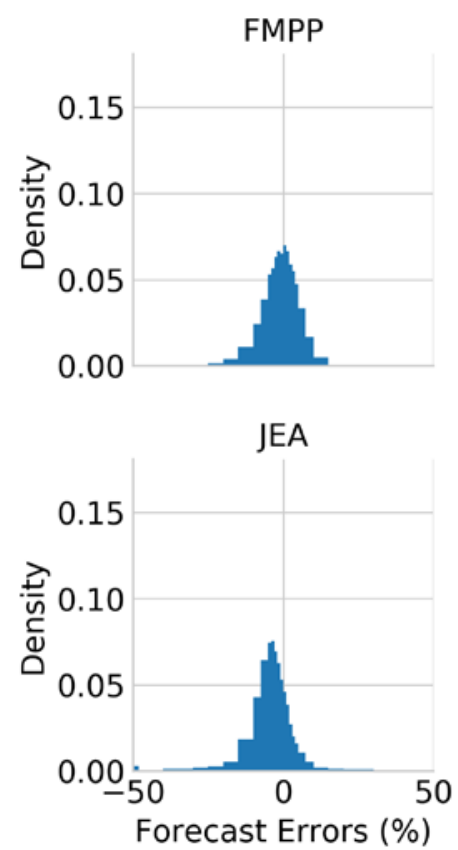
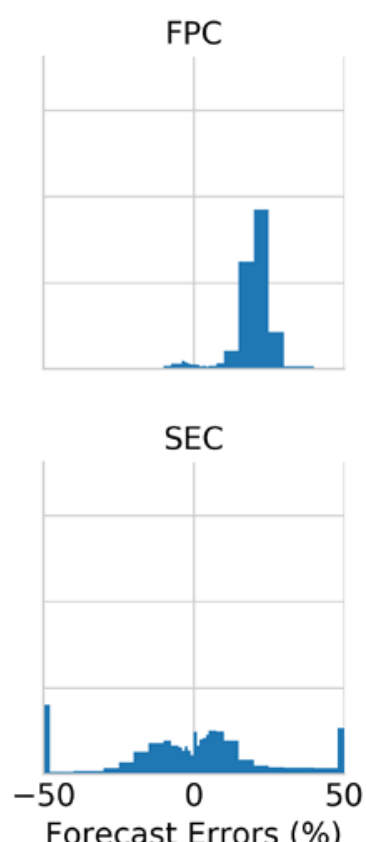

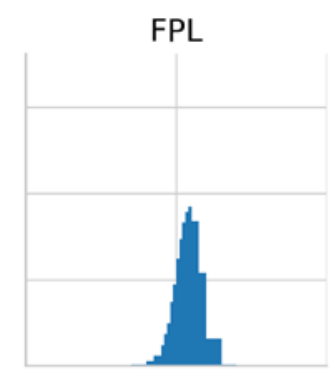

TAL

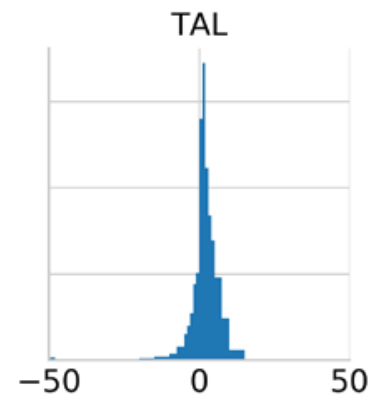

Forecast Errors (\%)

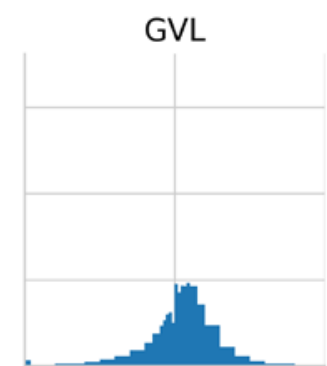

TEC

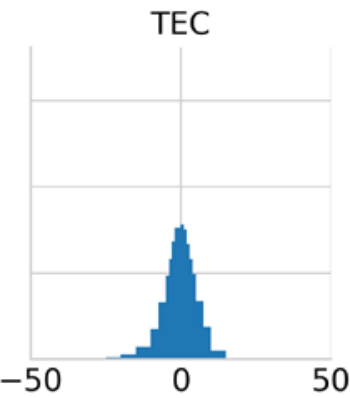

Forecast Errors (\%)

Figure 6. Historical day-ahead load forecast errors for FRCC balancing authorities as reported in EIA Form 930 for 2015-2019

Reported values are (Actual - Forecast) × 100/Actual. Positive values reflect underestimates of actual load and a need for up reserves; negative values reflect overestimates of actual load and a need for down reserves. Forecast errors outside the limits shown are placed in the first (FE $<-50 \%)$ or last (FE $>50 \%)$ bins.

The data in Figure 6 are used directly for the DA operational assumptions. For HA operations, we require estimates of hour-ahead load forecast errors. We construct such forecast errors by making the conservative assumption, which requires no additional data, that an hour-ahead forecast is constructed by assuming that the next hour's day-ahead forecast error will be the same as this hour's forecast error. This is a form of persistence forecast because we are assuming that a current observation (namely, the day-ahead load forecast error) will persist into the future. As with other forms of persistence forecast, this can be considered a conservative "forecast to beat".

Figure 7 illustrates this hour-ahead load forecast method by plotting study data for an example day. The top plot (a) shows how the hour-ahead forecast profile is generally closer than the dayahead forecast to the actual load profile. In the bottom plot (b), we can see how this is accomplished. When the day-ahead forecast errors are relatively constant for a period of time (e.g., during the evening of July 23), the persistence forecast assumption is good and the hourahead forecast errors are much smaller than the day-ahead forecast errors. The hour-ahead forecast errors are larger when the day-ahead forecast errors are changing from one hour to the next, but overall, the process tends to reduce the magnitude of errors in both directions. 
a) Hour-ahead load forecast

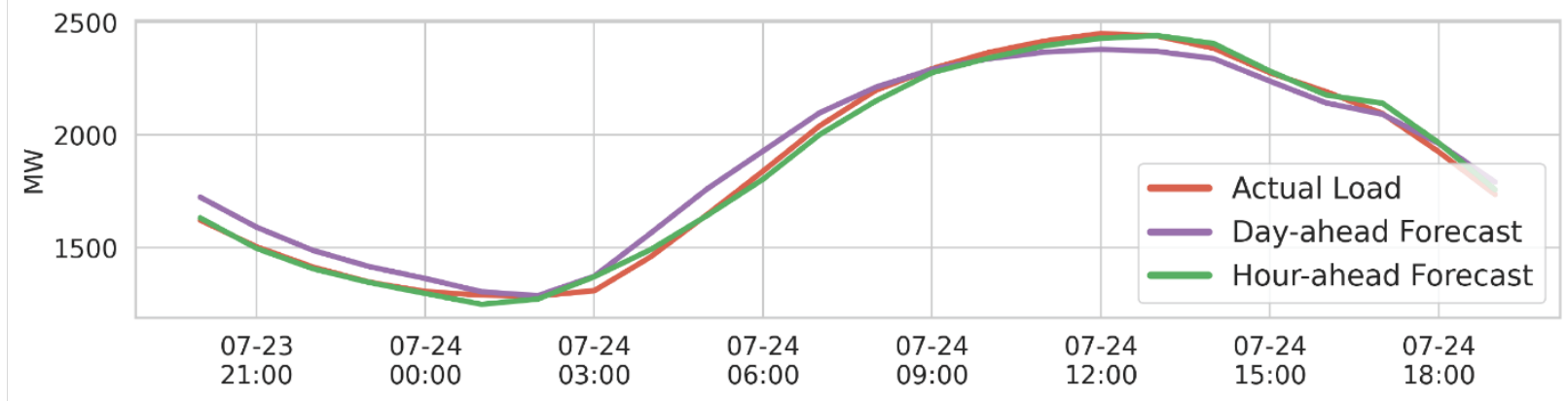

b) Day-ahead and hour-ahead forecast errors

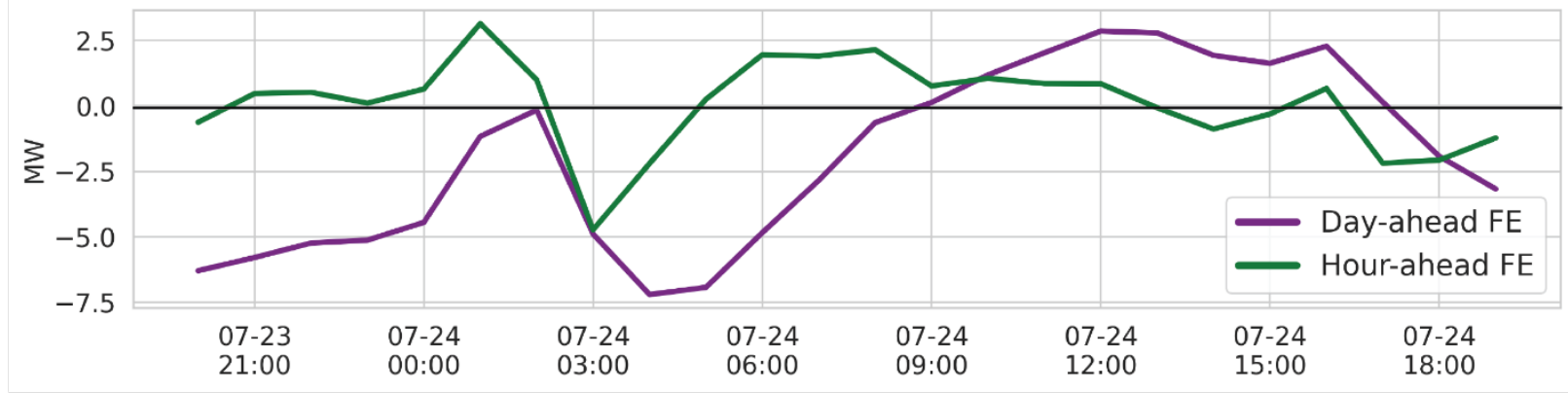

Figure 7. Hour-ahead load forecast made by persisting day-ahead forecast errors, illustrated for an example day

Top plot (a) shows actual, day-ahead forecast, and hour-ahead forecast load. Bottom plot (b) shows the resulting hour-ahead forecast errors alongside the historical day-ahead forecast errors.

Because we do not have measured sub-hourly load data, we do not create a data set of sub-hourly (e.g., 5-, 10-, or 15-minute) load forecast errors from which to estimate regulation reserve requirements for SH operations. Instead, we borrow the assumption from Lew et al. (2013) that $1 \%$ of load should be held for regulation reserve in this case.

\subsection{Solar Forecast Errors}

To construct solar forecast errors, we use the simulated "actual" and clear-sky generation in our solar data sets along with the notion of a "clear-sky persistence" forecast as described in Ibanez et al. (2012). Although highly conservative in the day-ahead case, we use this method to construct both day-ahead and hour-ahead forecasts. Fundamentally, the forecasts are constructed by assuming that the current time period's clear-sky fraction profile, computed by dividing actual solar generation by the clear-sky generation, will persist. Similar to the hour-ahead load forecast method, this assumption is conservative in the sense that it requires little data and is straightforward to compute.

Figure 8 shows how we construct day-ahead solar forecasts by assuming that tomorrow's clearsky fraction pattern will be the same as today's pattern. In the example shown, the day-ahead forecast errors for July 25 are quite large in the morning and early afternoon, but the day-ahead forecast profile for the late afternoon matches the actual profile quite well. Building a day-ahead solar generation forecast based on day-ahead weather forecast information would be expected to perform much better than this method almost all the time (Zhang et al. 2015). Thus, our results for DA operations that use these forecasts should be considered quite conservative from the 
standpoint of requiring more reserves to cover larger forecast errors than would likely be needed if weather-based day-ahead solar forecasts are used instead. Although it is outside the scope of this study to precisely quantify the improvements expected from incorporating weather forecasts, Section 5.3 provides a sensitivity analysis of DA reserve requirements for GVL if the day-ahead solar forecast errors are $50 \%$ or $75 \%$ smaller than our conservative estimates.

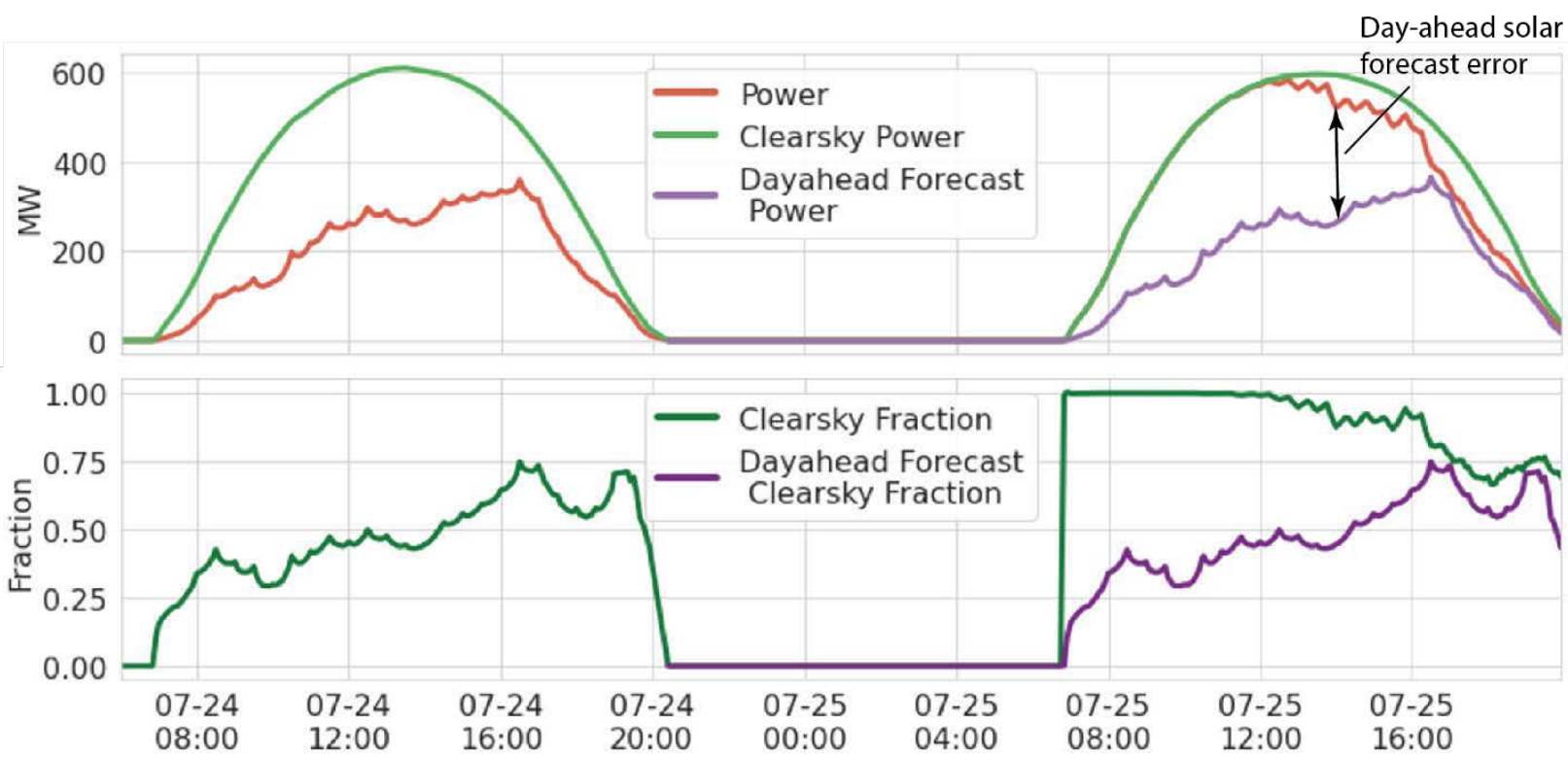

Figure 8. Example day-ahead solar forecast constructed using clear-sky persistence

The top plot shows clear-sky, actual, and forecasted generation. The bottom plot shows the corresponding actual and forecasted clear-sky fraction profiles.

Hour- and 5-minute-ahead solar forecasts are constructed by assuming that the clear-sky fraction in the current hour or 5-minute interval will persist to the next hour or 5-minute interval. The former is used for HA and SH operations; the latter only for SH operations. The forecast error distributions that result for all three forecast horizons, expressed as a fraction of nameplate PV capacity, are shown for three different example PV capacities in Figure 9. As expected, normalized solar forecast errors are smaller when the forecast horizon is shorter, the PV capacity is larger, or both. In our examples, the forecast horizon appears to make a larger difference than amount of PV, and the amount of PV is most influential at the hour-ahead scale. 


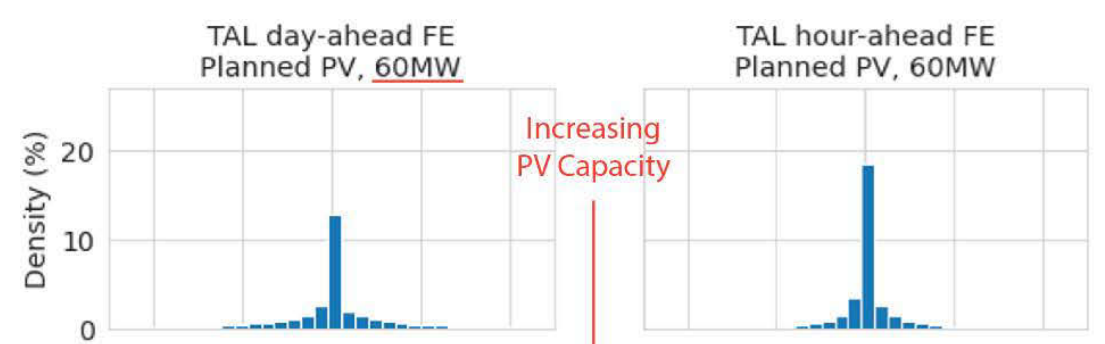

FPL day-ahead FE

Planned PV, $1007 \mathrm{MW}$
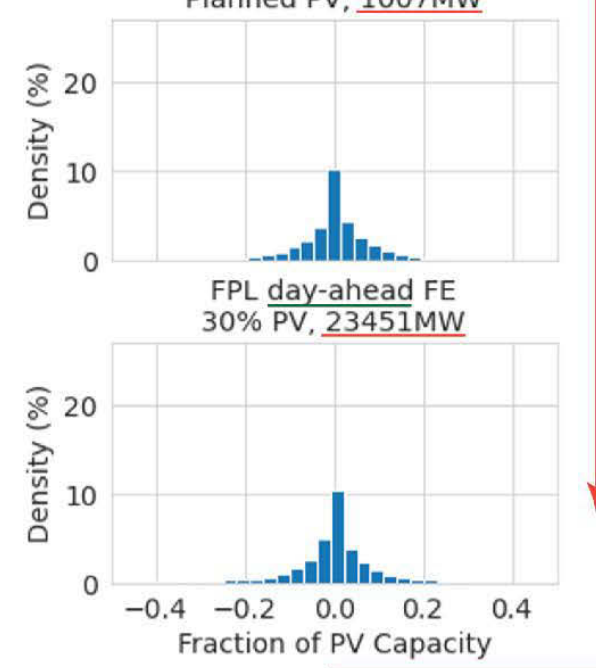

FPL hour-ahead FE Planned PV, 1007MW

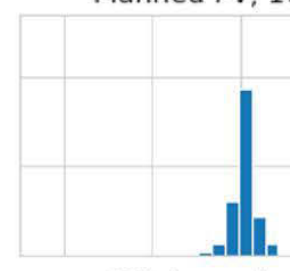

FPL hour-ahead FE

$30 \%$ PV, $23451 \mathrm{MW}$

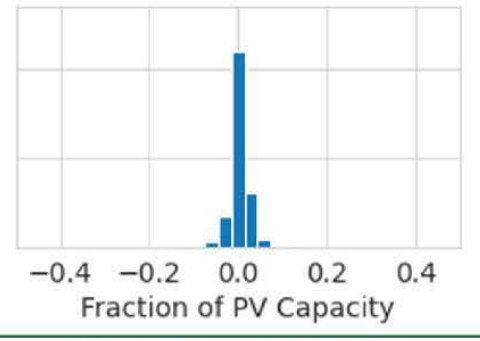

Shorter Forecast Horizon

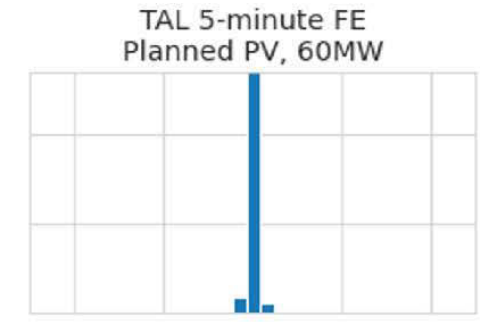

FPL 5-minute FE Planned PV, 1007MW

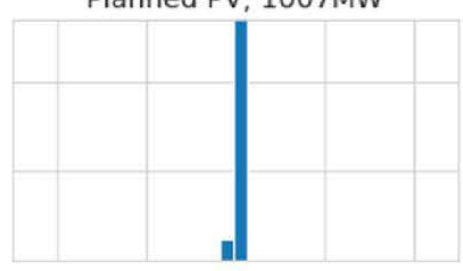

FPL 5-minute FE $30 \%$ PV, $23451 \mathrm{MW}$

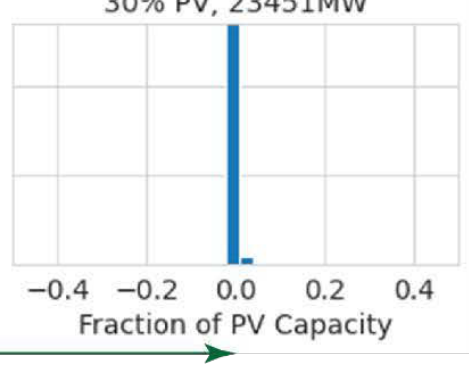

Figure 9. Solar forecast error distributions as a fraction of PV capacity

Examples for $60 \mathrm{MW}, 1.0 \mathrm{GW}$, and $23.4 \mathrm{GW}$ of PV capacity over day-ahead, hour-ahead, and 5-minute forecast horizons are shown.

\subsection{Calculating Reserve Requirements}

Estimates of how much reserve capacity is needed to operate smoothly in the face of load and solar forecast errors are calculated for each solar scenario and operational practice type by:

1. Considering the type of balancing reserves needed

2. Constructing corresponding forecast error databases and normalizing the resulting megawatts if necessary

3. Binning the forecast errors based on measurable characteristics

4. Computing percentile statistics per bin over both the positive and negative forecast errors separately

5. Binning the actual load and solar data

6. Applying the reserve levels computed in Step 4 to the binned data from Step 5.

This process produces up and down reserve estimates for load and solar separately. Following Ibanez et al. (2012), we combine the load and solar requirements into a total reserve requirement using the heuristic that the two components are similar to standard deviations taken from 
independent distributions. Thus, we have total reserve requirements $\left(\sigma_{\text {total }}\right)$ computed from load $\left(\sigma_{\text {load }}\right)$ and solar $\left(\sigma_{\text {solar }}\right)$ reserve requirements as:

$$
\sigma_{\text {total }}=\sqrt{\sigma_{\text {load }}^{2}+\sigma_{\text {solar }}^{2}}
$$

This means that although solar reserve requirements may be significant, they are not directly additive with load reserve requirements, which mutes their impact. An example of how this arithmetic works in practice is shown in Figure 10. For a simple example, if $\sigma_{\text {load }}=\sigma_{\text {solar }}=10$ $\mathrm{MW}$, the total reserve requirement is $14.1 \mathrm{MW}$, not $20 \mathrm{MW}$.

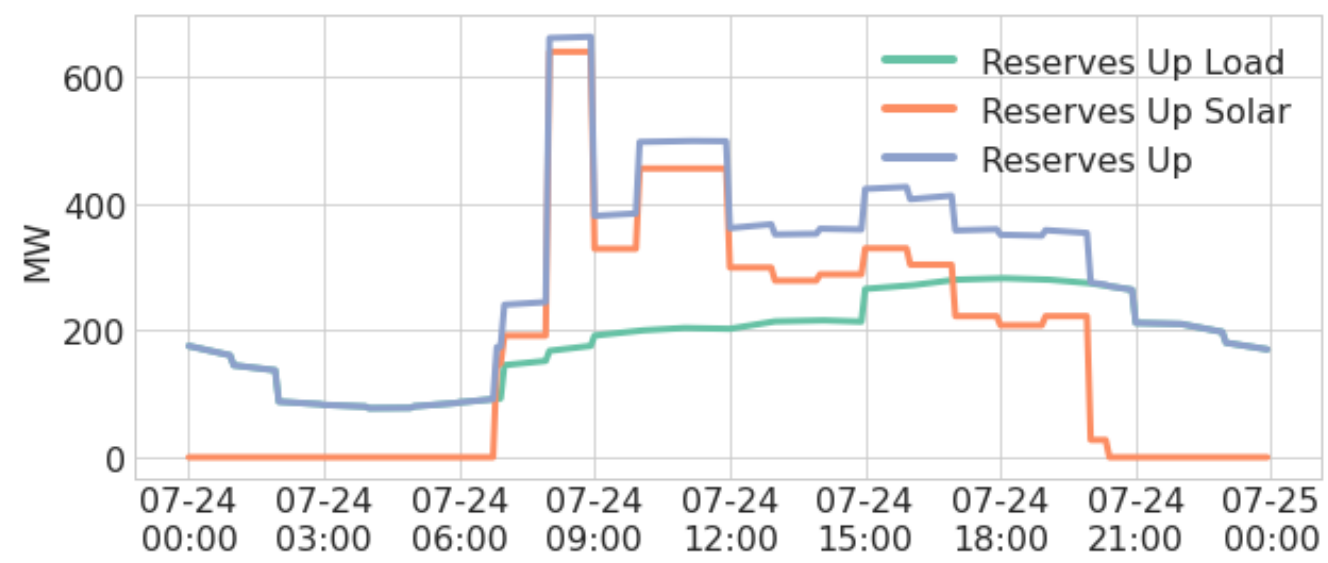

Figure 10. Illustration of the geometric sum of load and solar reserves

\subsubsection{Day-Ahead Reserve Requirements}

The process for estimating balancing reserve needs under day-ahead operational practice is shown in Figure 11. In this case, the key uncertainties are day-ahead load and solar forecast errors. ${ }^{10}$ The magnitude and distribution of day-ahead load forecast errors are taken directly from EIA Form 930 data, but prior to applying that information to the study's time-synchronized load and solar data sets:

- The EIA-930 actual load data are placed into 10 bins with an equal number of data points per bin and arranged from lowest (bin 0) to highest (bin 9) load levels.

- The forecast errors by percent of actual load are computed and partitioned into underestimates and overestimates.

- The percent of load levels needed for both up and down reserves is calculated per bin by covering a certain percentage (e.g., 95\%) of both the up and down forecast errors in each bin.

\footnotetext{
${ }^{10}$ This type of operational practice is uncommon in the United States. Furthermore, the reserve requirements being estimated here are fundamentally different from the reserves that are typically co-optimized in the day-ahead UC of most balancing authorities. Most balancing authorities ensure in the UC step that they will have enough reserves to balance supply and demand in real-time operations. Therefore, in that case, the reserves committed in the day-ahead are of a magnitude sufficient to cover real-time (5-minutes up to hourly) forecast errors. Here we are modeling the operations of a balancing authority that does not run SCED at regular intervals between the day-ahead UC and realtime operations; therefore, the reserves need to be sufficient to cover day-ahead forecast errors.
} 
These reserve levels (percent of load for up reserves and down reserves in each load bin) could then be applied to our separate time-synchronized load and solar data set. For solar, we used the day-ahead clear-sky persistence methodology depicted in Figure 8 to create day-ahead solar forecasts, calculated the resulting absolute (MW) forecast errors, and then computed up and down reserve requirements for each of 10 clear-sky ramp bins based on covering a certain percentage of forecast errors. The resulting megawatt reserve requirements, specified by direction (up/down) and clear-sky ramp bin (20 discrete reserve levels for all daylight hours) were then applied to all times in the data set based on each data point's clear-sky ramp bin. Because clear-sky ramp is defined as the clear-sky power at this time step minus the previous time step's clear-sky power, this binning process is generally correlated with time of day. In other words, morning hours have the most positive clear-sky ramp, whereas evening hours have the most negative clear-sky ramp.

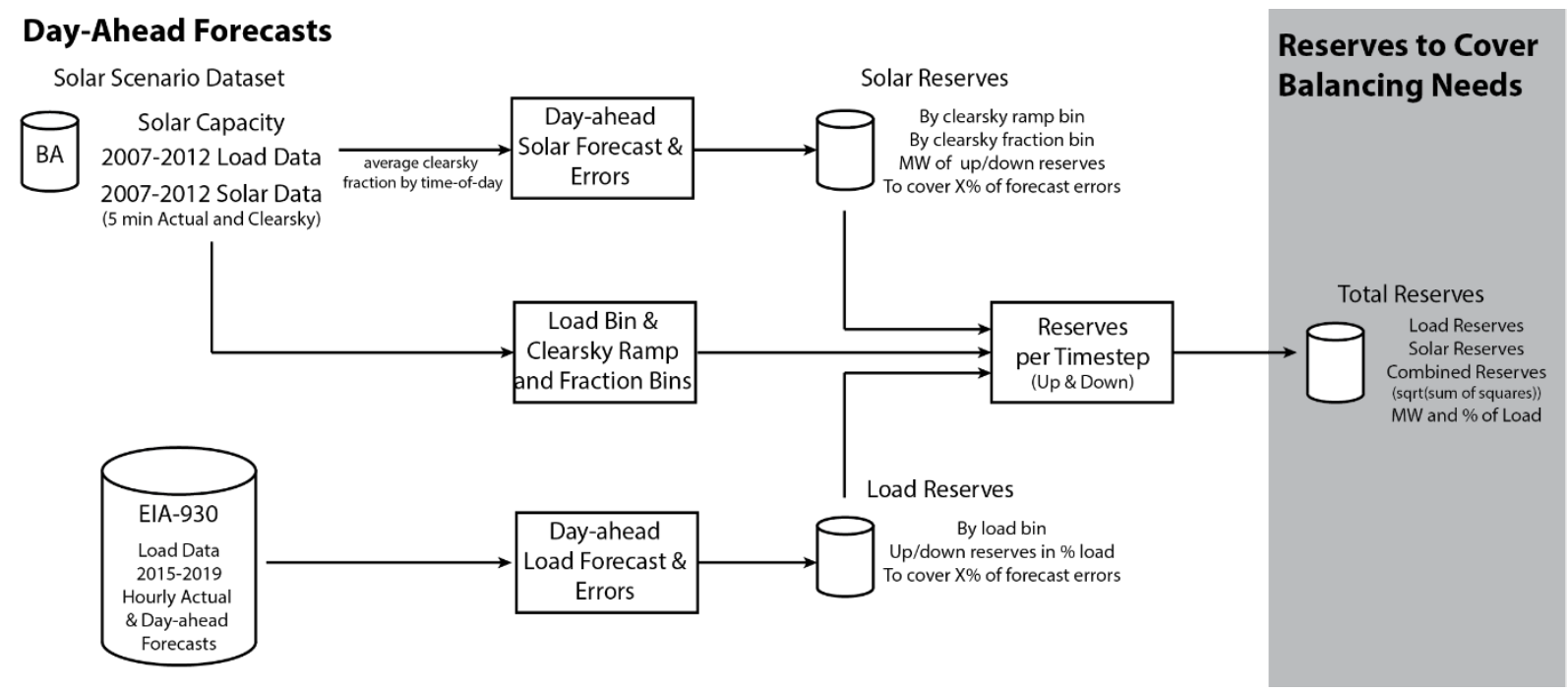

Figure 11. Study process for estimating reserve requirements under assumed day-ahead operational practices

Example reserve requirements for load are shown in Figure 12. ${ }^{11}$ The wide range of estimated reserve needs is a direct consequence of the observed historical day-ahead load forecast errors shown in Figure 6. Comparing the two levels of strictness-covering $80 \%$ or $95 \%$ of forecast errors, respectively - we see both that this parameter has a large impact on the results and that some utilities are impacted more than others, depending on the shapes of their forecast error distributions. For example, JEA seems to have a longer-tailed distribution for up reserves, especially on the highest load days; we see a similar situation for GVL's down reserves on lowload days.

\footnotetext{
${ }^{11}$ Load bin 0 is not shown in this plot because, as the lowest $10 \%$ of load, it tends to contain more outliers, many of which are likely associated with historical outages, and is therefore more difficult to interpret in a normal operations setting.
} 

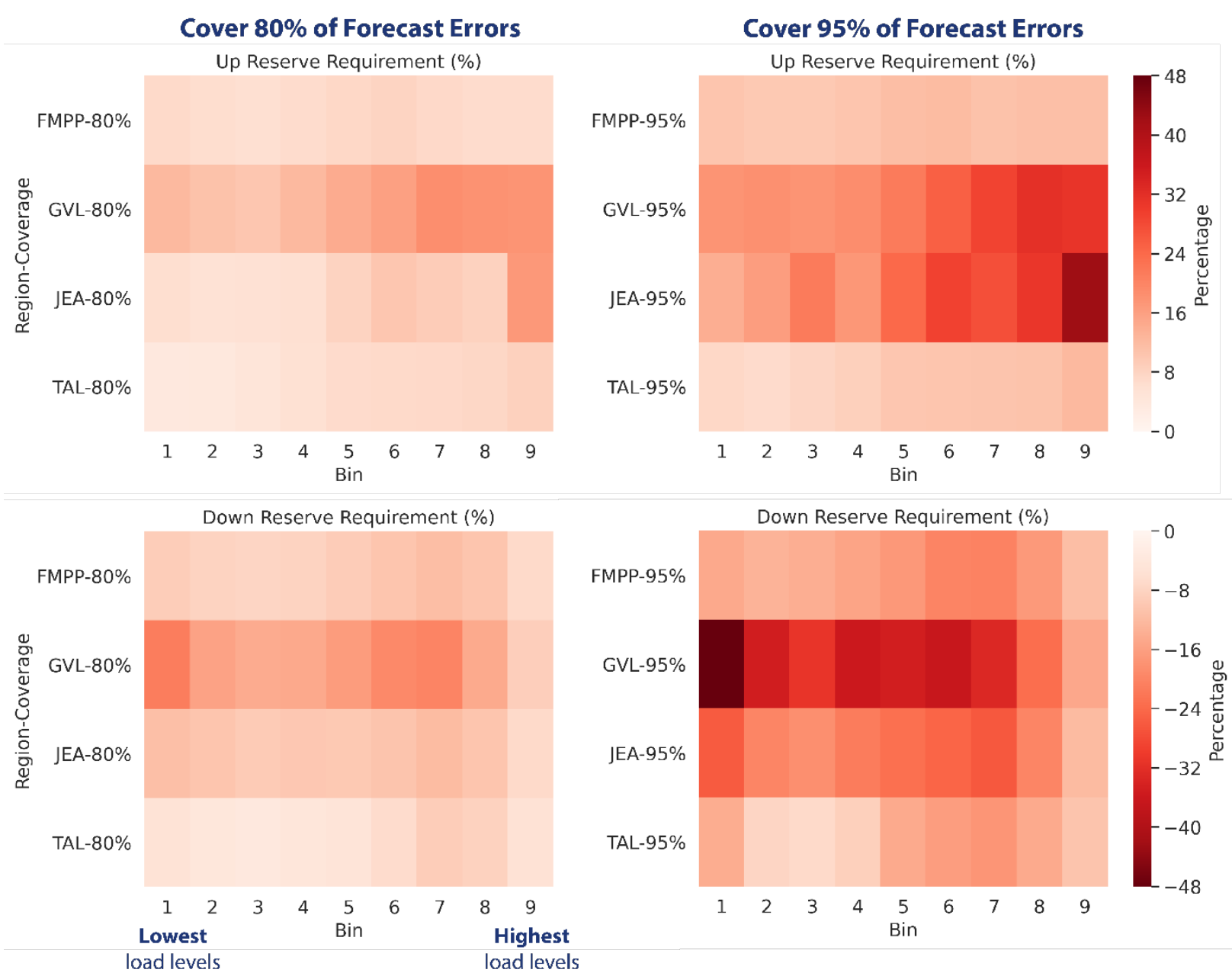

Figure 12. Municipal utility balancing reserve needs to cover day-ahead load forecast errors

Most municipal utilities do not need to hold this level of reserve in practice because their operations are better characterized as hour-ahead, rather than day-ahead.

Because the day-ahead clear-sky persistence forecast for solar generation does not incorporate any weather forecasting information, the forecast errors it produces can be quite large (Figure 9), and so we end up with conservative estimates for reserve need. For example, Figure 13 shows that reserves to cover $95 \%$ of day-ahead solar forecast errors in TAL could range from around $20 \%$ of nameplate capacity to nearly $50 \%$, depending on time of day and amount of PV deployed. The smaller amount of PV shown (60 MW, blue bars) requires more reserves as a proportion of nameplate capacity, presumably because the weather experienced by that quantity of co-located PV (at the Tallahassee airport) is so similar, producing highly correlated forecast errors. The larger amount of PV (584 MW, corresponding to about 30\% of TAL annual load, orange bars) averages out some of those forecasting errors, although estimated reserve need still ranges from about $20 \%$ (at sunset) to around $40 \%$ (during midday hours) of nameplate capacity. 


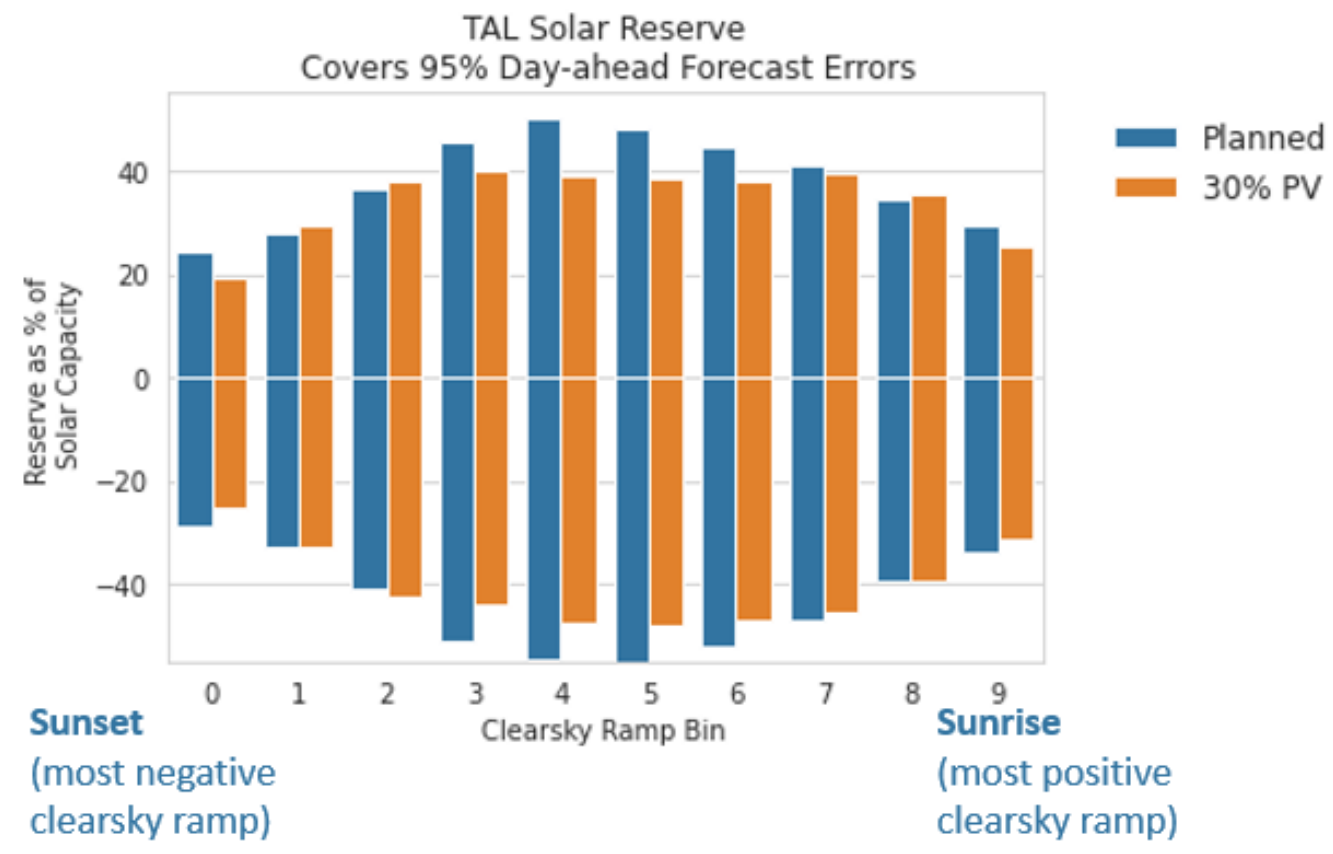

Figure 13. Example day-ahead solar reserve requirements based on day-ahead forecast errors, by clear-sky ramp bin and for two levels of solar generation in TAL

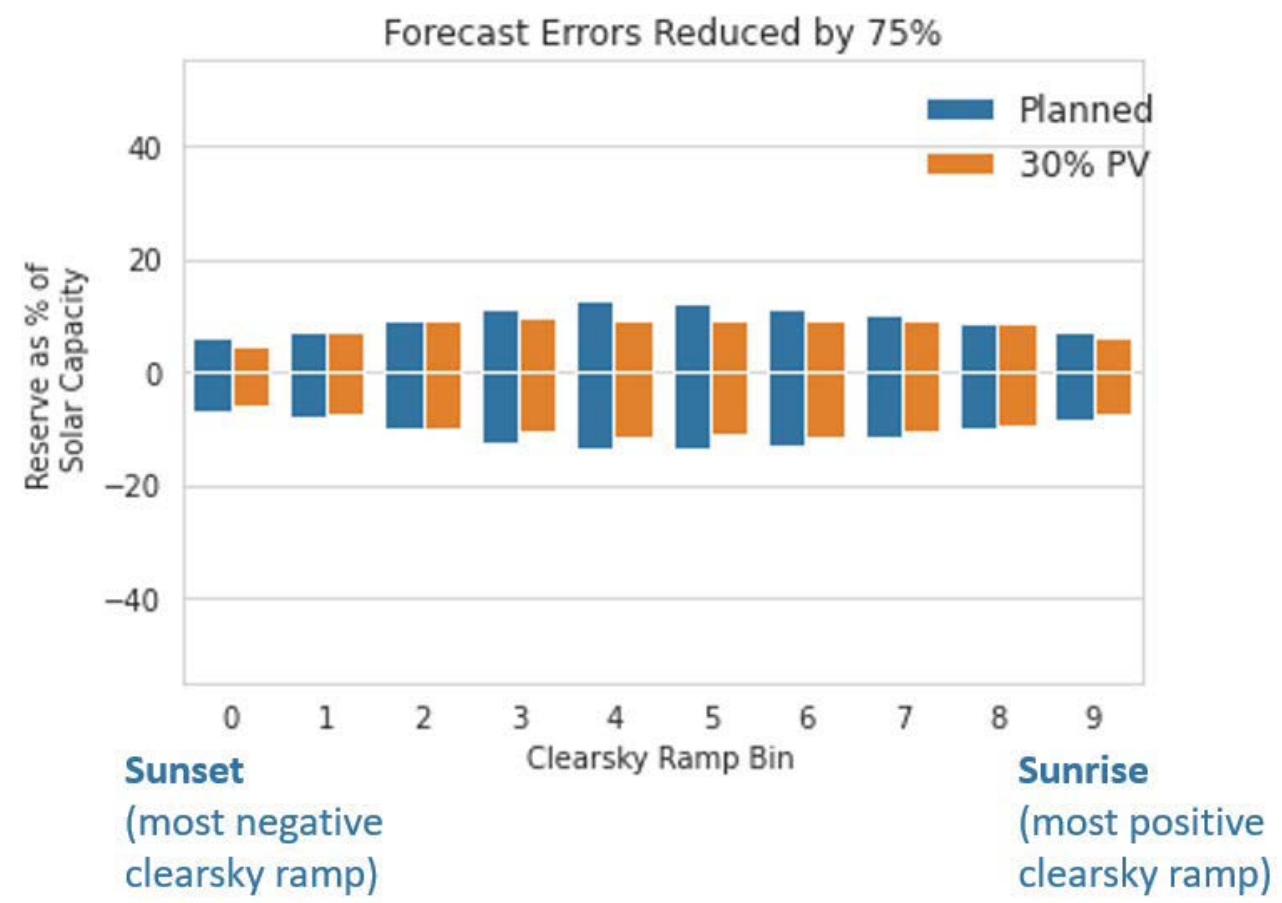

Figure 14. Example day-ahead solar reserve requirements based on $75 \%$ more accurate day-ahead forecast errors, by clear-sky ramp bin and for two levels of solar generation in TAL

However, if a better forecasting method yielded forecast errors $75 \%$ smaller than our conservative methodology, reserve requirements would similarly be reduced by about $75 \%$ (Figure 14). In this case, reserve needs for the $30 \% \mathrm{PV}$ scenario are always less than $10 \%$ of 
nameplate capacity. For the $60 \mathrm{MW}$ scenario, reserves needs in the middle of the day are between $10 \%$ and $15 \%$ of nameplate capacity.

\subsubsection{Hour-Ahead Reserve Requirements}

If in addition to day-ahead forecasts, unit commitment, and dispatch, utilities also adjust load and solar forecasts on an hourly basis and use that information to adjust dispatch, then the difference between dispatch point and actual demand depends on hour-ahead rather than day-ahead forecast errors. The process we use to estimate resulting reserve need is similar (Figure 14), but instead of directly using day-ahead load forecast errors, we are able to take advantage of hour-ahead information to tighten both load (Figure 7) and solar forecast (Figure 9, middle column compared to leftmost column) errors.

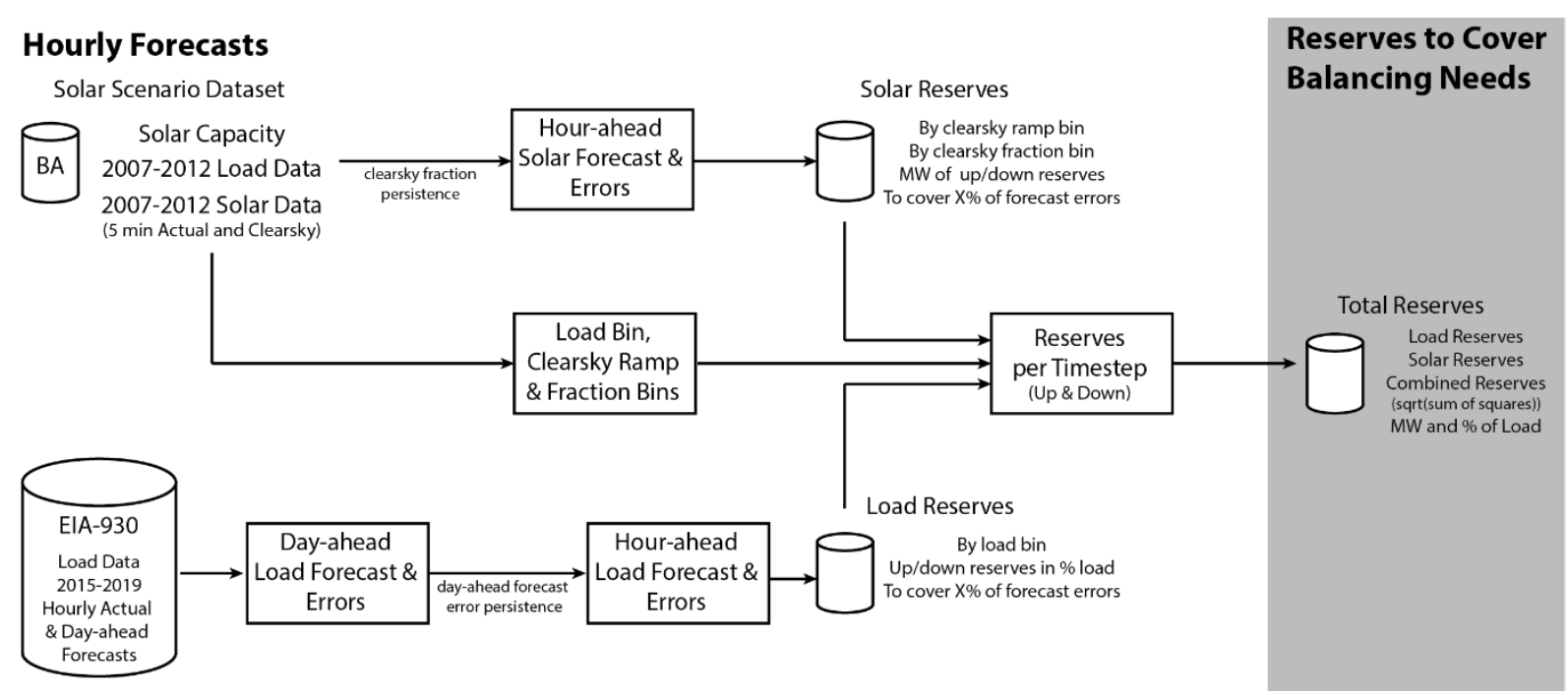

Figure 15. Study process for estimating reserve requirements under assumed hour-ahead operational practices

The process used to estimate reserve requirements that cover hour-ahead load forecast errors is shown in Figure 15. The main difference in the results compared to the analogous day-ahead load reserve requirements (Figure 12) is simply the percent of load that needs to be held in reserve - whereas the plot scale for day-ahead reserves went up to $\pm 48 \%$ of load, $\pm 18 \%$ of load is sufficient for up and down reserves to cover $95 \%$ of forecast errors in all of these cases. Similar to Figure 12, the story is different for different balancing authorities and percent of forecast errors covered. If covering only $80 \%$ of forecast errors is sufficient for smooth operations, reserve needs can be $10 \%$ or less of load in all cases. Carrying forward from the dayahead load forecast errors, GVL and JEA's load forecasts again do not appear to be as accurate as TAL and FMPP's, especially at the $95 \%$ coverage level. 


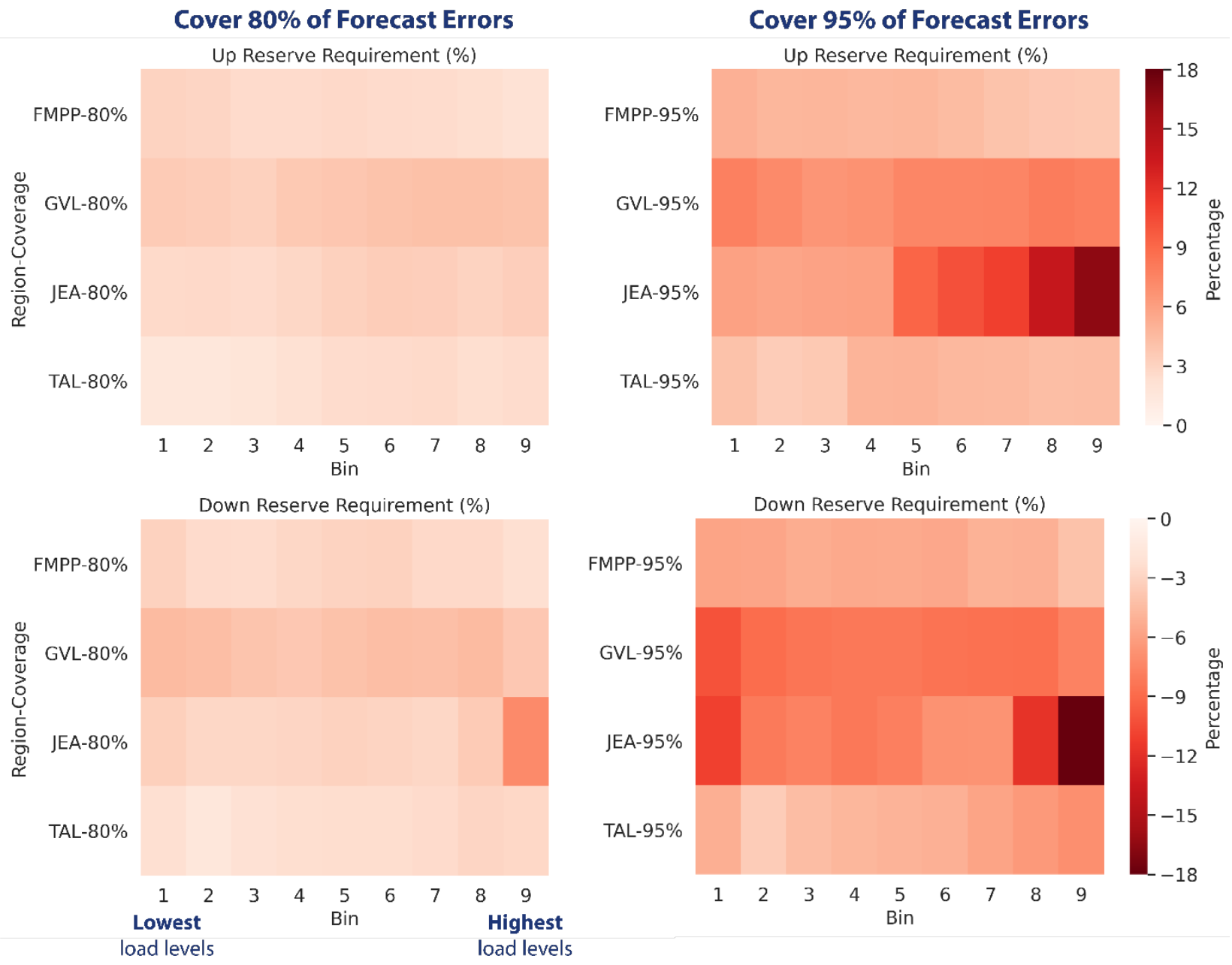

Figure 16. Municipal utility balancing reserve needs to cover hour-ahead load forecast errors

Note the color scale in this plot compared to Figure 12-hour-ahead uncertainty is generally much smaller than dayahead uncertainty because knowledge of how today's load has compared to the day-ahead forecast thus far provides a lot of information about expected behavior in the next hour.

For the hour-ahead solar reserve estimates, we bin not only on the clear-sky ramp, as we did in the day-ahead case, we also bin on the clear-sky fraction in the hour prior to the forecasted hour (i.e., at the time the forecast would be made). Because clear-sky fraction is 1 in clear conditions and 0 in dark conditions, the lowest bin numbers for that variable correspond to highly overcast conditions, whereas the highest bin numbers correspond to clear conditions and near-maximum output. As shown in Figure 16, more reserves in both directions (up reserves to cover overestimates of solar output and down reserves to make room for unforecasted but available solar generation) are generally needed under cloudy, as compared to clear conditions. Our conservative forecasting method of clear-sky persistence also leads to more reserve requirements in the morning because there is no hour-ahead data available to effectively prime the forecast. We start each day's hour-ahead forecasts with the last daytime clear-sky fraction available (i.e., the last clear-sky fraction registered on the previous evening). 

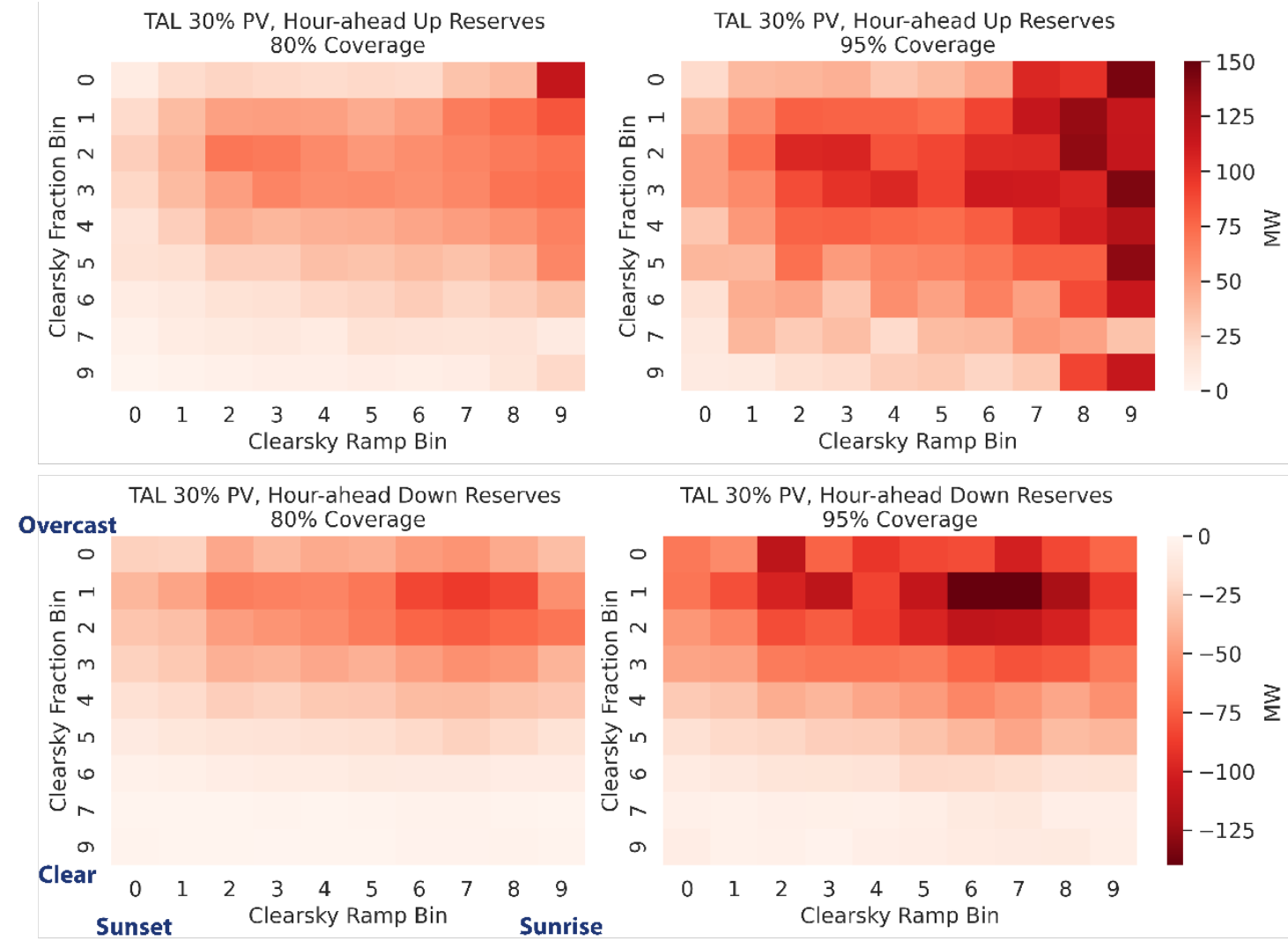

Figure 17. Estimated reserve needs to cover $80 \%$ and $95 \%$ of TAL hour-ahead solar forecast errors with 584-MW PV (about $30 \%$ of annual load), differentiated by up and down reserves

\subsubsection{Sub-Hourly Reserve Requirements}

Finally, sub-hourly reserve needs are estimated per Figure 17. In this case, we assume that two different types of balancing reserves are held and operated by the BA: (1) regulation reserves, which are resources that follow the AGC signal to balance supply and demand at the 4-second scale, and (2) flexibility or ramping reserves, which are held during day-ahead UC and any hourahead or less frequent re-dispatching processes to cover variable generation forecast errors over hour timescales, and then dispatched directly at the sub-hourly timescale (e.g., 5-15-minute dispatch) to directly address changing load and supply availability forecasts. 


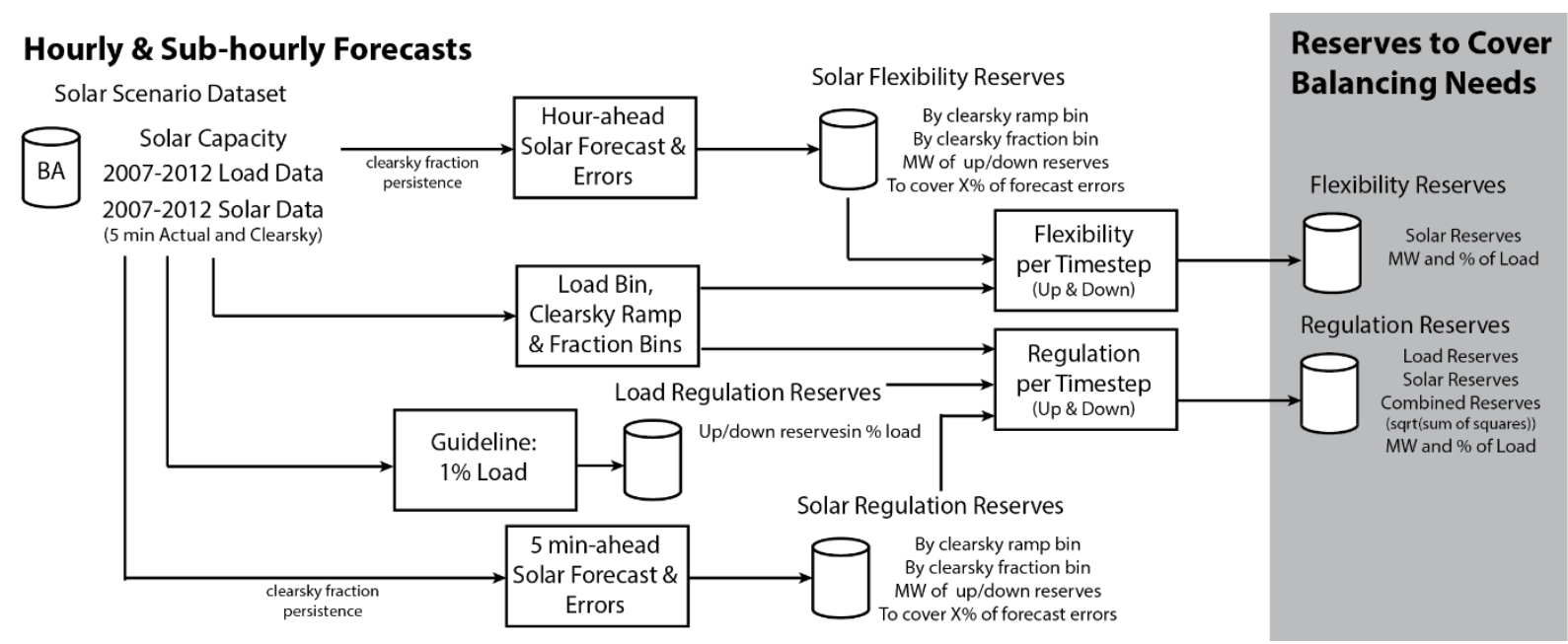

Figure 18. Study process for estimating reserve requirements under assumed hour-ahead operational practices

In this case, instead of directly estimating load forecast errors at a sub-hourly timescale, we assume per Lew et al. (2013) that holding regulation reserves equal to $1 \%$ of load will be sufficient to cover the load uncertainty portion of regulation reserve/AGC needs. Overall, this should be achievable given sufficient BA size, forecasting, and dispatch practices. The solar subhourly uncertainty, which is combined with the $1 \%$ of load per Equation 2 to form the overall regulation reserve requirement, is estimated by covering a specified percentage of 5-minuteahead clear-sky persistence forecast errors binned along the clear-sky ramp and clear-sky fraction dimensions (the same binning dimensions as for hour-ahead reserves, such as in Figure 16).

Based on the assumption of sub-hourly load and solar forecasts and system re-dispatch, flexibility reserves at the hourly level only need to address solar forecast uncertainty at the hourahead timescale; there is no additional load component. Furthermore, the hour-ahead solar forecasts described previously are reused here. Although flexibility and regulation reserves are dispatched differently (flexibility reserve capacity is explicitly dispatched at the sub-hourly intervals, whereas regulation reserve capacity follows the AGC signal), we typically present their arithmetic sum together, as a total amount of "balancing reserves."

\section{Results}

We study the reserve implications of a wide range of PV penetrations for different FRCC BAs and combinations thereof through the scenarios composed by selecting one value from each column in Table 5. All combinations shown were run for this study; however, the results focus on the municipal BAs using select PV penetrations, with all balancing reserves calculated assuming 95\% coverage of forecast errors and with PV placed at a random selection of 50\% of each BA's nodes. These key default focal points and parameter selections are shown in bold in the table. 
Table 4. Scenario Framework for Studying the Impact of PV on Reserve Needs Depending on BA Size and Operational Practice

\begin{tabular}{|c|c|c|c|c|}
\hline BAs & $\begin{array}{c}\text { PV (Approx. } \\
\text { Available } \\
\text { Generation as } \% \\
\text { of Annual Load) }\end{array}$ & $\begin{array}{c}\text { Operational } \\
\text { Practice }\end{array}$ & $\begin{array}{c}\text { Percent of } \\
\text { Forecast Errors } \\
\text { Covered }\end{array}$ & $\begin{array}{c}\text { PV Expansion } \\
\text { Nodes }\end{array}$ \\
\hline GVL & $\begin{array}{c}\text { Current } \\
\text { TAL }\end{array}$ & Day-ahead & $80 \%$ & $\begin{array}{c}\text { Current \& planned } \\
\text { PV nodes only }\end{array}$ \\
JEA & $5 \%$ & Hour-ahead & $95 \%$ & Rab-hourly \\
FMPP & $10 \%$ & & $99 \%$ & $\begin{array}{c}\text { Randomly } \\
\text { sected } 50 \% \text { of } \\
\text { all nodes }\end{array}$ \\
MUNIS (GVL, TAL, & $15 \%$ & & & \\
JEA, and FMPP) & $20 \%$ & & & \\
TEC & $25 \%$ & & & \\
FPC & $30 \%$ & & & \\
FPL & $35 \%$ & & & \\
FRCC (GVL, TAL, & $40 \%$ & & & \\
JEA, FMPP, TEC, & $45 \%$ & & & \\
FPC, FPL) & $50 \%$ & & & \\
\end{tabular}

a PV capacity operating as of fall 2018

b Current PV capacity plus deployments expected through 2024 as expected in 2018

In the remainder of this section, we examine where the BAs are now in terms of estimated reserve requirements given near-future, planned PV penetrations and current operational practice (Section 5.1). We then explore two options for reducing reserve requirements as solar penetrations increase through the particular lens of GVL (Section 5.2), examine the sensitivity of our DA results to smaller solar forecast errors (Section 5.3), and revisit the sensitivity of our results to the chosen percentage of forecast errors covered (Section 5.4). As explained in Appendix B, we found that our analysis results were not sensitive to how PV expansion nodes were selected.

\subsection{Current Reserve Requirements Depend on Balancing Authority Size and Operational Practices}

Based on the operational survey of FRCC municipal utilities (Section 3), we analyze GVL with DA operational practice and TAL, JEA, and FMPP with HA practice. We assume that TEC, FPC, and FPL operations are most similar to our SH assumptions. Figure 18 summarizes the reserve requirements estimated for each BA under these assumed current practices and PV penetrations estimated for 2024.

The median reserve requirements for these BAs vary greatly: from as low as $1.5 \%$ of load for FPC and FPL to as high as $25 \%$ and $10 \%$ of load for GVL and JEA, respectively (Figure 19, top panel). In general, reserve requirements as a portion of load decrease with increasing power system size and operational frequency, even though larger BAs tend to require more absolute megawatts of reserves (Figure 19, bottom panel). Here and in what follows, operational 
frequency encompasses the frequency of load and solar forecasts, as well as the frequency of dispatch.

Comparing regions that are similar in size - GVL with TAL and FMPP with TEC — we find that higher operational frequency leads to lower reserve requirements. Hourly operation in TAL results in much lower reserve requirements (with an interquartile range of $5 \%-6 \%$ of load) than does day-ahead operations in GVL (with an interquartile range of $19 \%-31 \%$ of load); sub-hourly operation in TEC results in lower median reserve requirements (3\% of load) as compared to hourly operations in FMPP (5\% of load). Overall, our findings are in line with others who have found that larger BAs have less load variability (Ela, Milligan, and Kirby 2011), access to more resources for balancing the system, and smoother VRE time series outputs (Holttinen et al. 2011; Ibanez et al. 2012).
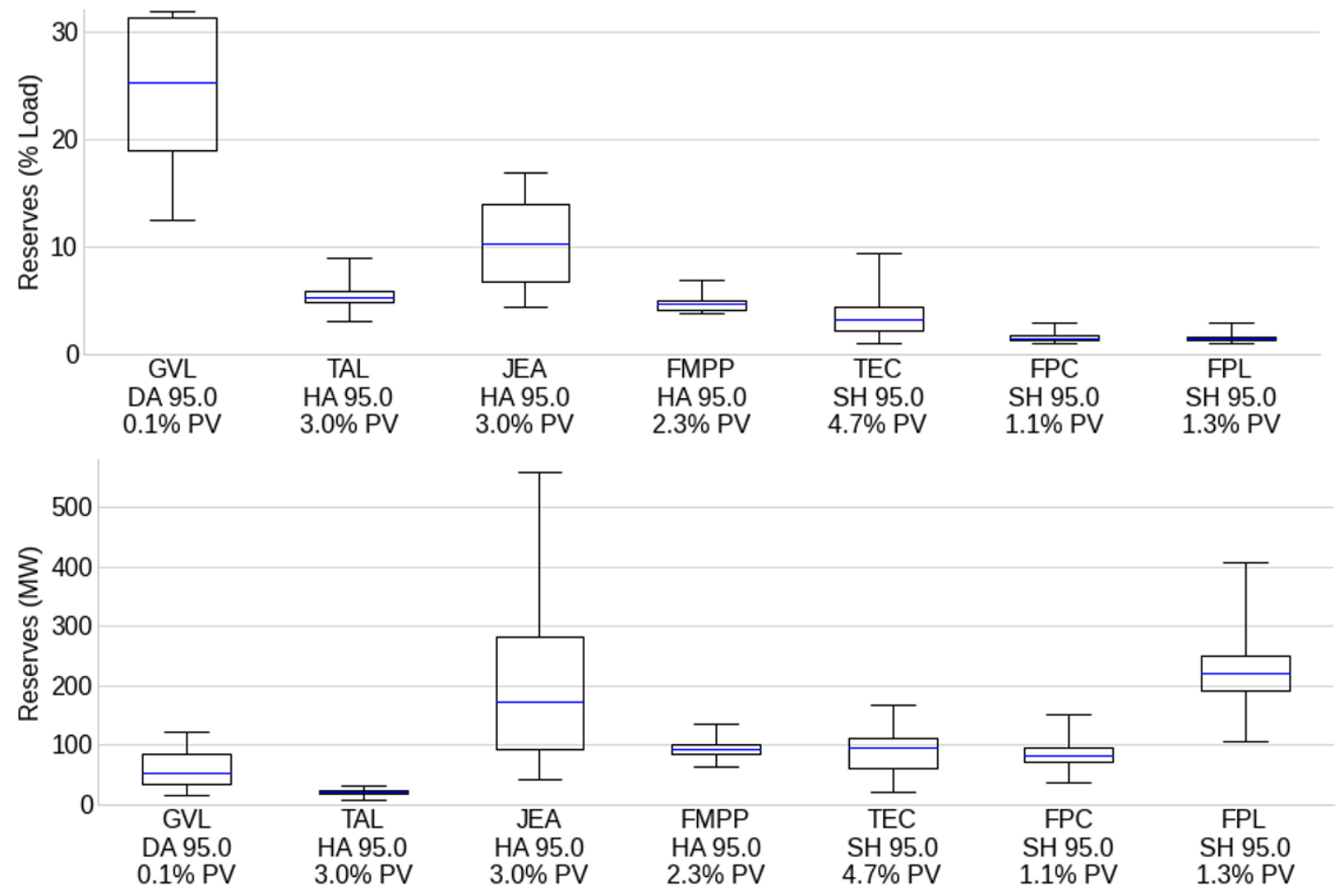

Figure 19. Up reserves needed to provide regulation and flexibility services with current operational practices and at planned PV penetration levels (top panel: as a percentage of load in each timestep; bottom panel: in absolute megawatts)

Blue lines show the medians; whiskers extend to the full range of the data. The labels on the $x$-axis indicate the region, modeled operational practice, forecast error coverage (95.0 means covering $95 \%$ of the balancing authority's load and solar forecast errors), and estimated PV penetration levels in 2024.

\subsection{Reserve Requirements at Different PV Penetrations}

All BAs face more variability and uncertainty as they integrate more PV into their systems (Ibanez et al. 2012; Halamay and Brekken 2010). We illustrate this for our context using three selected BAs in Figure 19: as GVL (with DA operations), TAL (with HA operations), and FPL 
(with SH operations) add more PV-from less than 3\% of BA load to about $15 \%$ and to about $30 \%$ - the reserve requirements increase both as a percentage of load (top panel) and in absolute megawatts (bottom panel). As the penetrations increase, the reserve requirements also increase from median values of $53 \mathrm{MW}$ to $138 \mathrm{MW}$ for GVL, $20 \mathrm{MW}$ to $62 \mathrm{MW}$ for TAL, and $220 \mathrm{MW}$ to 1,126 MW for FPL. Comparing across regions, we again find that more frequent forecasts and dispatch have a significant impact on reducing the required reserves. For example, GVL and TAL annual load is similar, around 1.73 TWh and 2.93 TWh, respectively; however, similar PV penetrations yield very different levels of estimated reserve need. At PV penetrations around $30 \%$, GVL's reserve requirement with day-ahead operations reaches $61 \%$ of load (median value), whereas TAL's reserve requirement with hourly operation is only around $16 \%$ (median value).
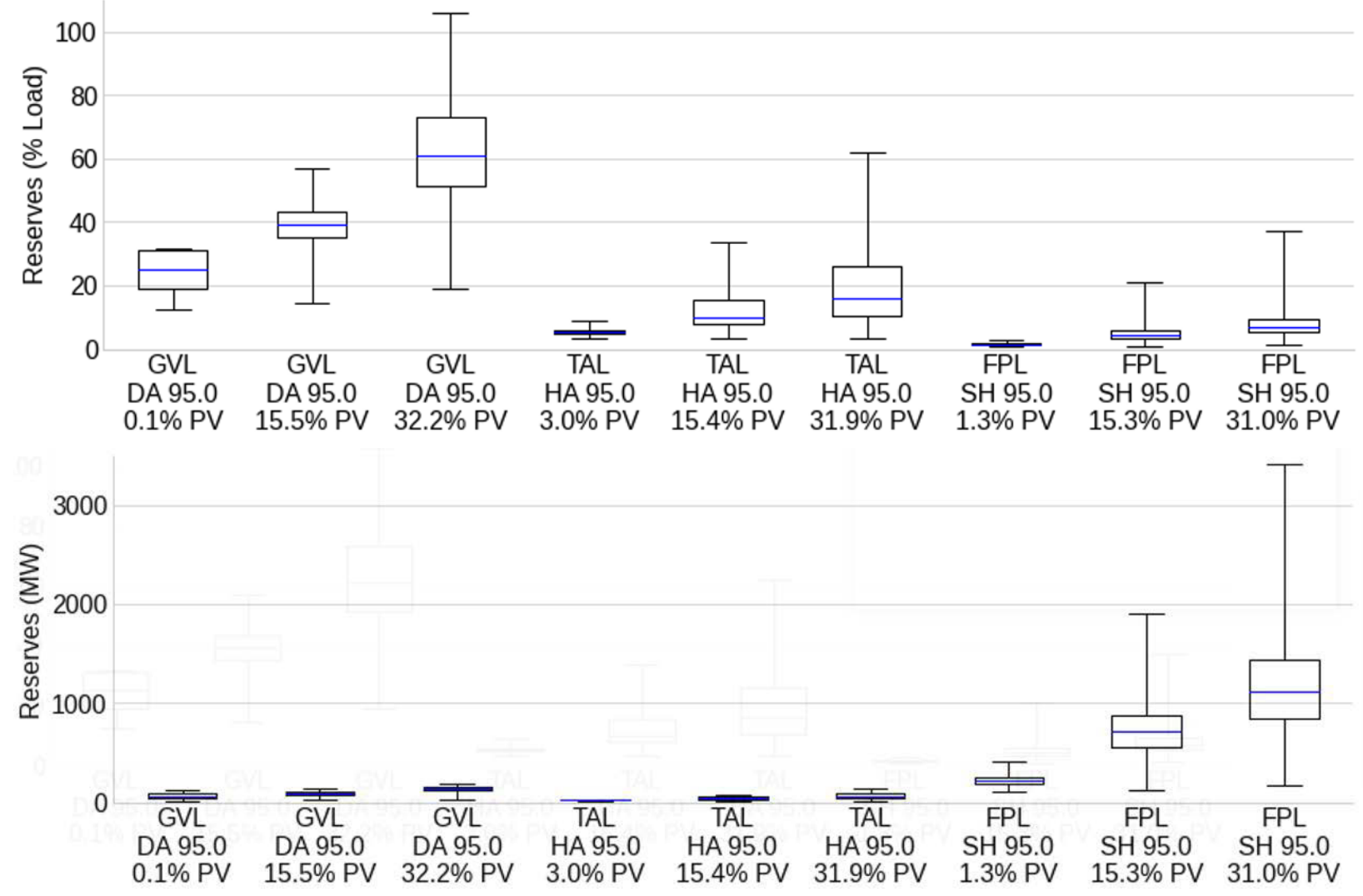

Figure 20. Up reserves (top: as a percentage of load in each timestep; bottom: in megawatts) needed to provide regulation and flexibility services at current and future PV penetration levels

Blue lines show the medians; whiskers extend to the full range of the data. The labels on the $x$-axis indicate the region, modeled operational practice, forecast error coverage (95.0 means covering $95 \%$ of the balancing authority's load and solar forecast errors), and PV penetration levels.

Both GVL and TAL's reserve requirements are significantly larger than FPL's as a percentage of load, presumably because of their relative size as compared to FPL. Two potential measures to limit the impact of higher solar PV penetrations on small BA reserve requirements are increasing operational frequency and coordinating operations with other BAs. 


\subsubsection{Mitigation Option 1: Increase Operational Frequency}

Figure 20 shows the impact of increasing operational frequency for the example of GVL moving from day-ahead to hourly operations for forecasting, quick-start unit commitment, and dispatch. At around 30\% solar PV penetration, moving from day-ahead operation to hourly operation reduces the median reserve requirement from about $60 \%$ to about $20 \%$ as a percentage of load. This corresponds to a difference of medians in absolute terms of $87 \mathrm{MW}$. Although more frequent forecasts alone do not necessarily lead to reduced reserve requirements (Neves, Brito, and Silva 2016), more frequent forecasts and dispatch can provide multiple benefits, including reduced reserve requirements, reduced generator cycling, and the attendant economic savings (Milligan et al. 2011, 2015; Ibanez et al. 2012).

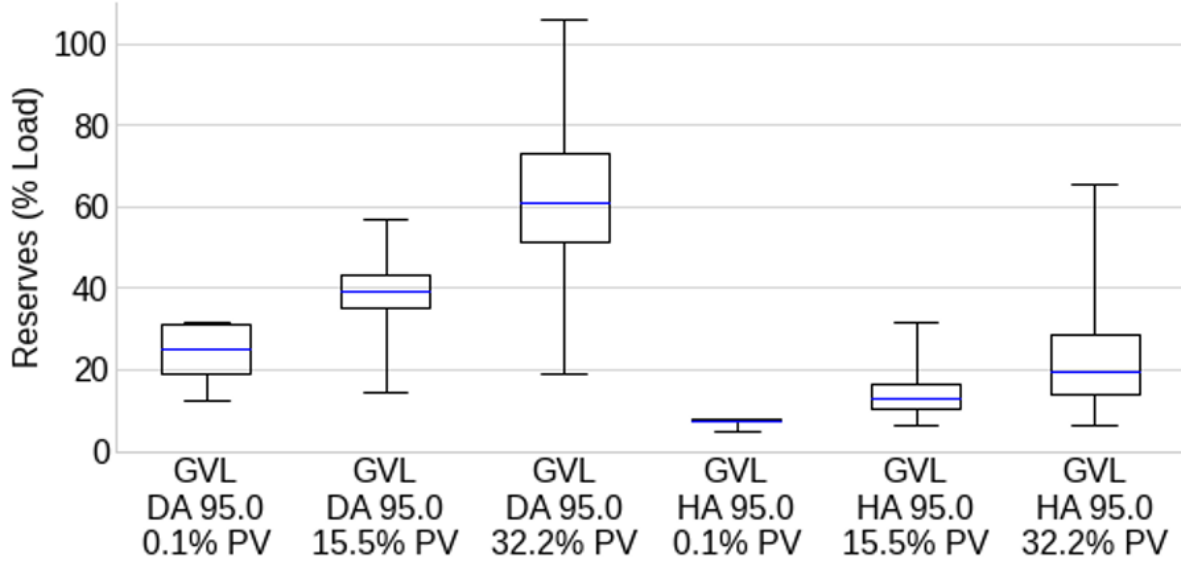

Figure 21. Up reserves needed (as a percentage of load in each timestep) to provide regulation and flexibility services in GVL at current and future PV penetration levels with day-ahead or hourly operation

Blue lines show the medians; whiskers extend to the full range of the data. The labels on the $x$-axis indicate the region, modeled operational practice, forecast error coverage (95.0 means covering $95 \%$ of the balancing authority's load and solar forecast errors), and PV penetration levels.

\subsubsection{Mitigation Option 2: Coordinate Operations with Other Balancing Authorities}

The second way to reduce reserve requirements is through balancing area coordination, such as forming an operating reserve sharing group. In a reserve sharing group, two or more balancing authorities collectively maintain, allocate, and supply the operational reserves for each balancing authority to maintain system reliability (Makarov et al. 2010; Katz, Denholm, and Cochran 2015). Forming an operational reserve sharing group by sharing regulation and flexibility services among GVL, TAL, JEA, and FMPP (i.e., a fictitious "reserve sharing group", MUNIS), for example, can reduce the reserve requirements for an individual balancing area (Figure 21). In this case, the reserve requirement for GVL at around $30 \% \mathrm{PV}$ penetration is reduced from around $20 \%$ of load to around $10 \%$ of load (median values) if GVL is part of MUNIS. This finding is consistent with previous studies on the potential benefits of balancing area coordination in the western United States (King et al. 2012; Samaan et al. 2017).

A more subtle point is also evident in Figure 21. Namely, as modeled in this study, sub-hourly operations alone would not necessarily reduce overall reserve requirements for GVL. This is because the hour-ahead solar uncertainty is the same and covered by both the HA and $\mathrm{SH}$ 
operational practice categories. The only difference in total reserve requirement therefore comes down to SH regulation reserve requirements (1\% of load combined geometrically with 5-minute solar forecast errors) compared to geometrically combining hour-ahead load reserve requirements with the aforementioned hour-ahead solar reserve requirements in the HA case. However, although total $\mathrm{SH}$ balancing reserve requirements are similar to or even larger than HA balancing reserve requirements, they are composed of two distinct types of reserve: regulation and flexibility, the latter of which tends to be less costly to procure and operate (see Section 2).

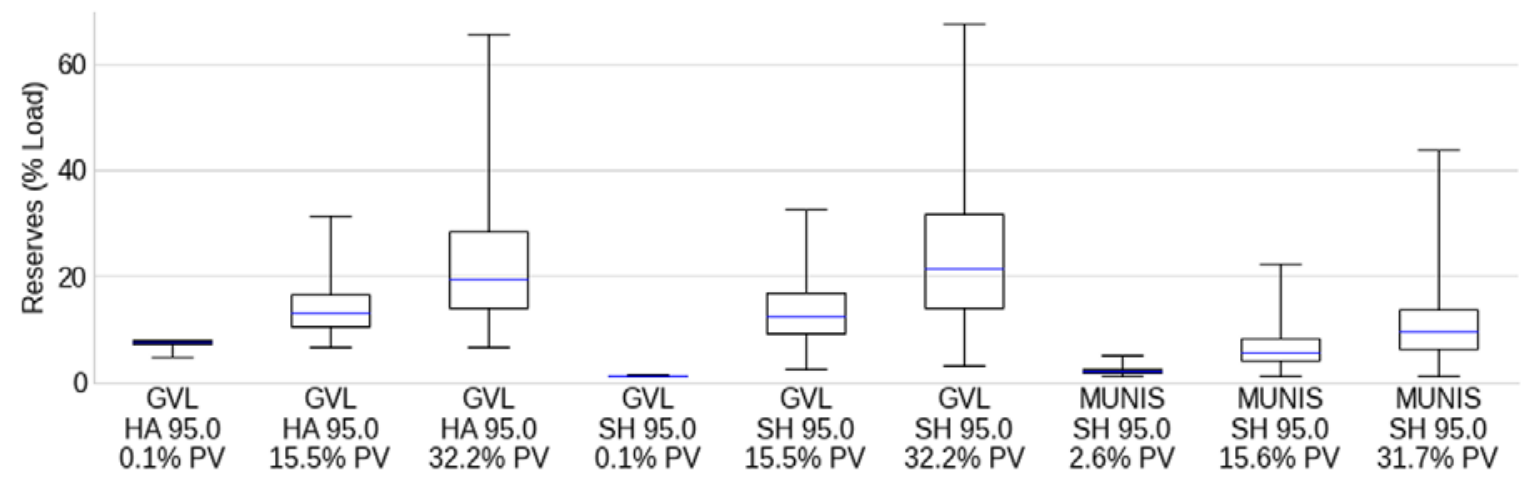

Figure 22. Up reserves needed (as a percentage of load in each timestep) to provide regulation and flexibility services under different PV penetration levels in GVL and MUNIS

Blue lines show the medians; whiskers extend to the full range of the data. The labels on the $\mathrm{x}$-axis indicate the region, modeled operational practice, forecast error coverage (95.0 means covering $95 \%$ of the balancing authority's load and solar forecast errors), and PV penetration levels.

\subsection{Sensitivity to Accuracy of Day-Ahead Solar Forecast}

As stated earlier, the solar forecast methods used for this analysis are low-data and easy to implement, but also conservative because they do not use any weather forecast information. This is especially true for our day-ahead solar forecasts - day-ahead solar forecasts informed by dayahead weather forecasts would be expected to have significantly lower forecast errors than those used in the mainline of this analysis (Zhang et al. 2015). To highlight the potential impact of more accurate day-ahead solar forecasts, we present a sensitivity analysis in which our day-ahead solar forecast errors were reduced (in both directions) by $50 \%$ or $75 \%$. The up reserve results for GVL at planned, 16\% and 32\% PV penetrations are shown in Figure 22. 


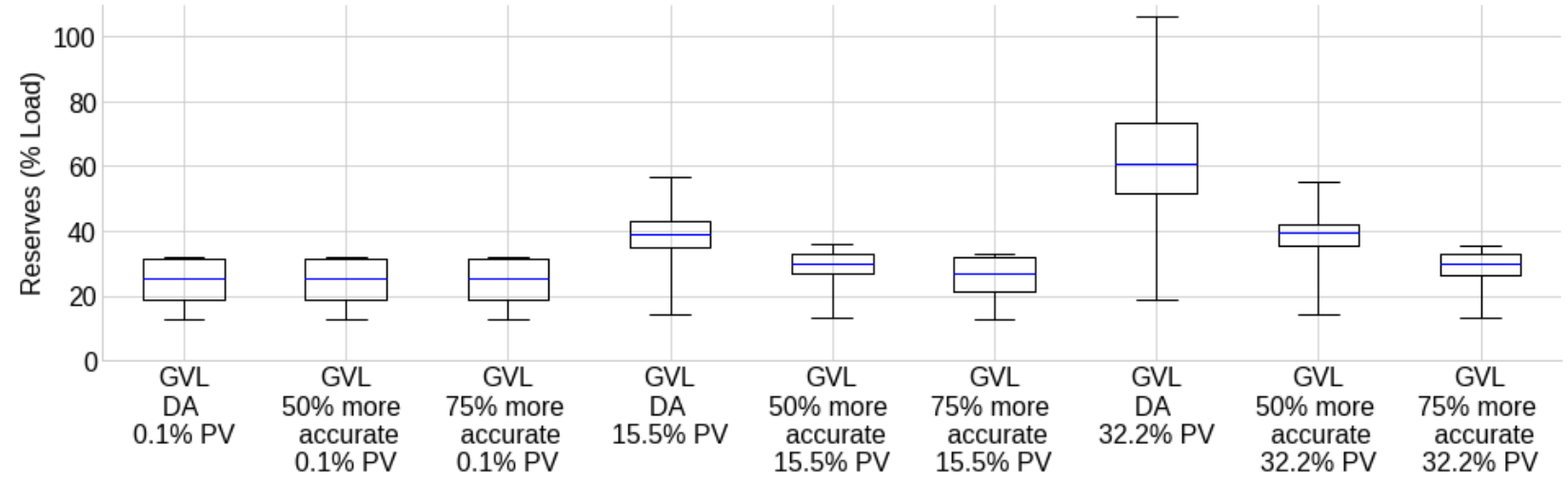

Figure 23. Up reserves needed (as a percentage of load in each timestep) in GVL using day-ahead operation with different day-ahead solar forecast accuracies at planned, $16 \%$, and $32 \%$ PV penetration and covering $95 \%$ of load and solar forecast errors

Blue lines show the medians; whiskers extend to the full range of the data. The labels on the $\mathrm{x}$-axis indicate the region, modeled operational practice, and PV penetration levels.

As PV penetration increases, higher forecast accuracy leads to significant reductions in DA reserve needs. At 32\% solar PV penetration, the median reserve need drops from $61 \%$ of load $(138 \mathrm{MW})$ to $30 \%$ of load $(61 \mathrm{MW})$ when forecast errors are reduced by $75 \%$. There are two key takeaways from this finding. First, incorporating day-ahead solar forecasts (based on weather forecasts) into GVL current operational practice may be sufficient to integrate up to $30 \% \mathrm{PV}$. Second, moving to hour-ahead operational practice or coordinating with other balancing authorities would still be worthwhile, as the reserve needs in those cases (median reserves around $20 \%$ or $10 \%$ of load, respectively) are significantly smaller than our most optimistic case for DA operational practice (around 30\% for day-ahead clear-sky persistence solar forecast errors reduced by $75 \%$ ).

\subsection{Sensitivity to Percent of Forecast Errors Covered}

There is no consensus on how to set reserve requirements in terms of what percentage of forecast errors should be covered. Ortega-Vazquez and Kirschen (2008) provide the conceptual framework that reserve quantities should be selected to minimize cost of reserves plus the expected societal cost of outages this level of reserves cannot prevent, but the resulting calculation is highly system-dependent. Indeed, we find a wide range of assumptions in the literature: Krad, Ibanez, and Gao (2016) reviewed reserve methods ranging from a static requirement to reserve requirements based on $50 \%, 70 \%, 90 \%$, and $95 \%$ of hour-ahead load (and variable generation) forecast error; Holttinen et al. (2008) note that in the sigma method, the multiples of sigmas have been around $6 \sigma$ for regulation reserves and $2 \sigma-3 \sigma$ for load following reserves and that at $3 \sigma$, the reserves could cover $99 \%$ of the variations (Holttinen et al. 2012). Ela et al. (2010) describe a Minnesota wind study and the Eastern Wind Integration and Transmission Study as using similar methods to combine reserve requirements from wind and load, but the former multiplied the result by 5 whereas the latter used a factor of 3 . Lew et al. (2013) use a regulating reserve requirement that is the geometric sum of $1 \%$ of load plus $95 \%$ of the 10-minute forecast errors from wind and PV, and a flexibility reserve requirement equal to the geometric sum of $70 \%$ of the hour-ahead forecast errors from load, wind, and PV (Ibanez et al. 2014). A Swiss case study uses $99.9 \%$ based on the "Swissgrid confidence threshold" (Abrell et al. 2019). Krad et al. (2016) further summarizes the lack of consensus in the field as: 
"Reserve strategies are typically developed in response to operating challenges in a given footprint, which has led to a lack of industry-wide standards regarding the calculation of operating reserve requirements and the effect that variable generation (VG) has on them. This is true for both contingency and, especially, regulation reserves."

Due to this lack of consensus in both research studies and real-world practice, we choose $95 \%$ forecast error coverage for the majority of results reported in the study, with the caveat that should a higher coverage be used, the estimated reserve requirements would increase, and conversely, a lower level of coverage results in lower reserve requirements.

More specifically, the example of FPL (Figure 23) demonstrates this impact and how it varies with PV penetration. As PV penetration level increases from around $1 \%$ to around $20 \%$, higher forecast error coverage leads to more significant increases in reserve needs. These results also generally show alignment between our results at 95\% coverage and the CEM assumptions described in Section 2, which also assumed 95\% coverage, because they were based on Ibanez et al. (2012).

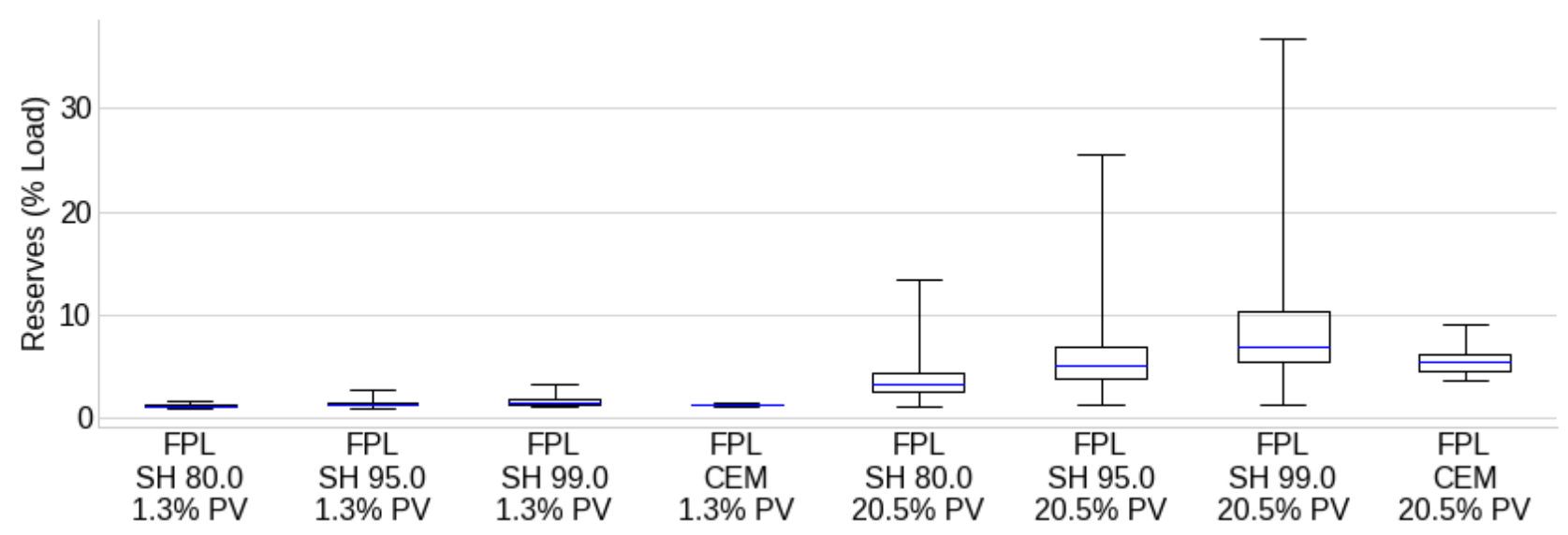

Figure 24. Up reserves needed (as a percentage of load) in FPL with sub-hourly operation covering different percentages of forecast errors at current PV penetration

Blue lines show the medians; whiskers extend to the full range of the data. The labels on the $x$-axis indicate the region, modeled operational practice, forecast error coverage (95.0 means covering $95 \%$ of the balancing authority's wind and solar forecast errors), and PV penetration levels. The CEM method covers $95 \%$ of solar forecast errors, $10-$ minute-ahead errors for regulating reserves, and 1-hour-ahead errors for flexibility reserves. The regulating reserve requirements are the geometric combination of the solar requirements and 1\% of load (Ibanez et al. 2012).

To examine the impact of forecast error coverage on reserve requirements more broadly, we calculate the reserve requirements for each region at about $30 \% \mathrm{PV}$ with HA or SH operational practice, depending on system size. When the forecast error coverage increases from $80 \%$ to $99 \%$, the reserves required as a percentage of load increases in all BAs and reserve sharing groups regardless of their operational practice (Figure 24), though the impact is much greater in smaller BAs with hourly operation than in larger BAs with sub-hourly operation (comparing the top panel of Figure 24 with the bottom panel). 

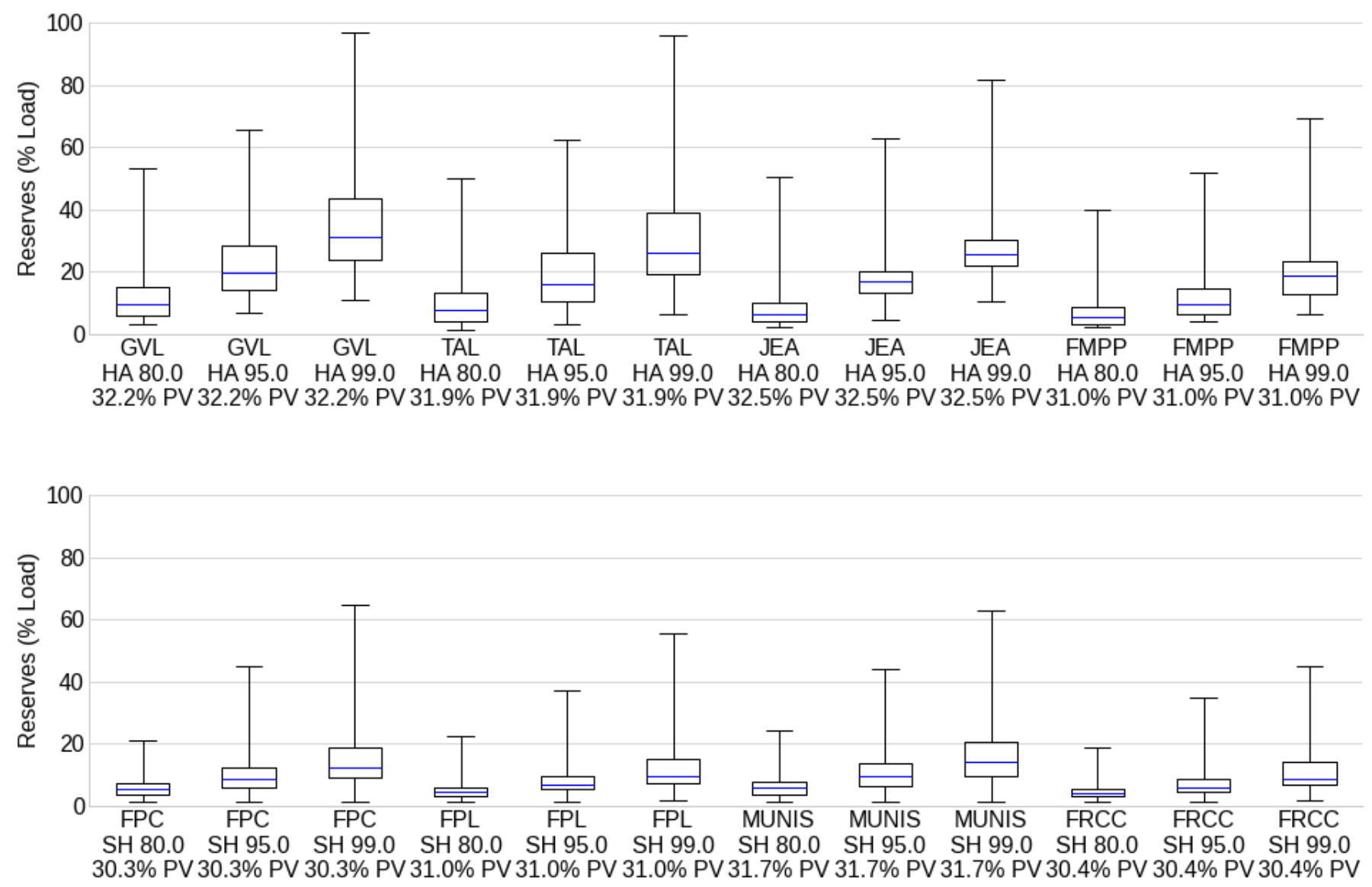

Figure 25. Up reserves needed (as a percentage of load) in smaller BAs with hourly operation (top panel) and larger BAs with sub-hourly operation (bottom panel) covering different percentages of forecast errors under around $30 \%$ PV penetration

Blue lines show the medians; whiskers extend to the full range of the data. The labels on the $x$-axis indicate the region, modeled operational practice, forecast error coverage (95.0 means covering $95 \%$ of the balancing authority's wind and solar forecast errors), and PV penetration levels.

\section{Conclusions}

Previous studies have demonstrated how reserve needs increase with increasing solar penetration. However, that body of work is underdeveloped on the question of reserve needs for small BAs with increasing amounts of solar generation. By working with Florida BAs of different sizes through the FAASSTeR project, the authors came to appreciate this lack of actionable, quantitative information as well as the importance of operational practice, given the likelihood of smaller BAs operating with less frequent forecasting and dispatch. In this study, we explore how both aspects of smaller BAs-less PV capacity across a smaller footprint and different operational practices - impact reserve requirements over a range of PV penetrations, and how large reserve requirements at high PV penetration can be mitigated.

Regarding the Florida municipal utilities and how their operational practices may need to change as they deploy more solar PV, we conclude the following: 
- FRCC balancing authorities' reserve needs currently depend on power system size and operational practices. All else equal, smaller balancing authorities and less frequent forecasts lead to greater reserve requirements (measured as a fraction of load).

- Increasing solar deployment increases reserve requirements for all balancing authorities. For the same PV penetration, the reserve requirements (measured as a fraction of load) are less for larger balancing authorities with more frequent forecasts and dispatch.

- Moving from day-ahead to hour-ahead load and solar forecasting and system dispatch could enable FRCC's smallest municipal balancing authority, GVL, to incorporate about $30 \%$ solar generation with median reserves around $20 \%$ instead of $30 \%$ to $60 \%$ of load. (Median day-ahead reserves of $60 \%$ reflect the conservative, low-data solar forecasting methodology used in this study, while the 30\% lower bound reflects $75 \%$ improvement on that benchmark, as may be achievable with weather forecast-based solar forecasts.)

- If all Florida municipal utilities collectively procured operational reserves, this could again halve GVL's reserve requirements at 30\% solar generation, reducing the median requirements to about $10 \%$ of load. For comparison, the median reserve needs of an "FRCC" reserve sharing group at 30\% PV would be about $6 \%$ of load (all else equal).

- Reserve needs vary greatly depending on how much forecast uncertainty is covered. For example, if all Florida municipal utilities collectively procured operational reserves and had a PV penetration of about 30\%, the median reserve requirements could be anywhere from $5.5 \%$ to $14 \%$ of load assuming the "right" level of uncertainty to cover falls between $80 \%$ and $99 \%$. This range overlaps with the analogous range for all of FRCC analyzed together, which is $3.5 \%$ to $9.0 \%$ of load.

Although we did not analyze reserve requirements from a rigorous, BA-specific NERC reliability perspective and used conservative, low-data "persistence" forecasts when historical data on forecast errors were not available, this analysis demonstrates clear, quantified trends that can help guide utility decisions regarding operational changes in support of PV integration. Solar forecasting, operational forecast and dispatch frequency, and operational footprint are first-order drivers of reserve need with increasing PV capacity. It appears that BAs of all sizes have options for integrating more solar with affordable reserve costs relative to current practice. 


\section{References}

Abrell, Jan, Patrick Eser, Jared B. Garrison, Jonas Savelsberg, and Hannes Weigt. 2019.

"Integrating Economic and Engineering Models for Future Electricity Market Evaluation: A Swiss Case Study.” Energy Strategy Reviews 25 (August): 86-106.

https://doi.org/10.1016/j.esr.2019.04.003.

Aydin, Nazli Yonca, Elcin Kentel, and H. Sebnem Duzgun. 2013. “GIS-Based Site Selection Methodology for Hybrid Renewable Energy Systems: A Case Study from Western Turkey." Energy Conversion and Management 70 (June): 90-106. https://doi.org/10.1016/j.enconman.2013.02.004.

Blair, Nate, Nicholas Diorio, Janine Freeman, Paul Gilman, Steven Janzou, Ty Neises, and Michael Wagner. 2018. "System Advisor Model (SAM) General Description (Version 2017.9.5)."

Bloom, Aaron, Aaron Townsend, David Palchak, Joshua Novacheck, Jack King, Clayton Barrows, Eduardo Ibanez, et al. 2016. "Eastern Renewable Generation Integration Study."

Bolinger, Mark, Joachim Seel, Dana Robson, and Cody Warner. 2020. "Utility-Scale Solar Data Update: 2020 Edition.” Berkeley, CA.

Brancucci Martinez-Anido, Carlo, Benjamin Botor, Anthony R. Florita, Caroline Draxl, Siyuan Lu, Hendrik F. Hamann, and Bri Mathias Hodge. 2016. "The Value of Day-Ahead Solar Power Forecasting Improvement.” Solar Energy 129 (May): 192-203. https://doi.org/10.1016/j.solener.2016.01.049.

Buster, Grant, Michael Rossol, Galen Maclaurin, Yu Xie, and Manajit Sengupta. 2021. "A Physical Downscaling Algorithm for the Generation of High-Resolution Spatiotemporal Solar Irradiance Data." Solar Energy 216: 508-17. https://doi.org/10.1016/j.solener.2021.01.036.

CAISO. 2010. "Integration of Renewable Resources: Operational Requirements and Generation Fleet Capability at 20\% RPS."

—. 2015. “Flexible Ramping Product: Revised Draft Final Proposal.” Folsom, CA.

_. 2020. "Flexible Ramping Product Refinements Final Proposal."

CASIO. 2020. “2019 Annual Report on Market Issues \& Performance.” Folsom, CA.

City of Gainesville. 2018. "Resolution No. 180442.” 2018. https://gainesville.legistar.com/LegislationDetail.aspx?ID=3697405\&GUID=3CD4A8734D4C-4F5E-B635-CFE99D412BF3.

City of Orlando. 2017. “100\% Renewable Energy Resolution.” 2017. https://orlando.novusagenda.com/AgendaPublic/CoverSheet.aspx?ItemID=42540\&Meeting $\mathrm{ID}=922$. 
City of Tallahassee. 2019. "Resolution No. 19-R-04.” Tallahassee, FL.

EIA. 2019. "2018 Form EIA-861.” 2019. https://www.eia.gov/electricity/data/eia861/.

Ela, Erik, Brendan Kirby, Eamonn Lannoye, Michael Milligan, Damian Flynn, Bob Zavadil, and Mark O'Malley. 2010. "Evolution of Operating Reserve Determination in Wind Power Integration Studies.” In IEEE PES General Meeting, PES 2010. https://doi.org/10.1109/PES.2010.5589272.

Ela, Erik, Michael Milligan, and Brendan Kirby. 2011. "Operating Reserves and Variable Generation." Golden, CO.

Ela, Erik, Michael R. Milligan, Aaron Bloom, A. Botterud, A. Townsend, and T. Levin. 2014. "Evolution of Wholesale Electricity Market Design with Increasing Levels of Renewable Generation.”

FERC. 2006. "Security Constrained Economic Dispatch: Definition, Practices, Issues and Recommendations."

2015. "Form No. 714 - Annual Electric Balancing Authority Area and Planning Area Report.” 2015. https://www.ferc.gov/industries-data/electric/general-information/electricindustry-forms/form-no-714-annual-electric/data.

Florida Public Service Commission. 2019. "Review of the 2019 Ten-Year Site Plans of Florida's Electric Utilities."

. 2020. "Review of the 2020 Ten-Year Site Pans of Florida's Electric Utilities." Tallahassee, FL.

FMEA. 2020. "Florida Municipal Utility Map.” 2020. https://www.publicpower.com/floridamunicipal-utility-map\#\%23.

FRCC. 2019. "FRCC Regional Entity Transition to SERC.” 2019. https://www.frcc.com/TRANS/SitePages/Home.aspx.

Garni, Hassan Z. Al, and Anjali Awasthi. 2017. "Solar PV Power Plant Site Selection Using a GIS-AHP Based Approach with Application in Saudi Arabia." Applied Energy 206 (November): 1225-40. https://doi.org/10.1016/j.apenergy.2017.10.024.

Haaren, Rob Van, Mahesh Morjaria, and Vasilis Fthenakis. 2012. "Empirical Assessment of Short-Term Variability from Utility-Scale Solar PV Plants." Progress in Photovotaics: Research and Applications. https://doi.org/10.1002/pip.2302.

Halamay, Douglas A., and Ted K.A. Brekken. 2010. "A Methodology for Quantifying Variability of Renewable Energy Sources by Reserve Requirement Calculation.” In 2010 IEEE Energy Conversion Congress and Exposition, ECCE 2010 - Proceedings, 666-73. https://doi.org/10.1109/ECCE.2010.5617946. 
Halamay, Douglas A., Ted K.A. Brekken, Asher Simmons, and Shaun McArthur. 2011.

"Reserve Requirement Impacts of Large-Scale Integration of Wind, Solar, and Ocean Wave Power Generation." IEEE Transactions on Sustainable Energy 2 (3): 321-28.

https://doi.org/10.1109/TSTE.2011.2114902.

Hale, Elaine T., Brady L. Stoll, and Joshua E. Novacheck. 2018. "Integrating Solar into Florida's Power System: Potential Roles for Flexibility." Solar Energy 170 (August): 741-51. https://doi.org/10.1016/j.solener.2018.05.045.

Holttinen, H., M. Milligan, E. Ela, N. Menemenlis, J. Dobschinski, B. Rawn, R. J. Bessa, D. Flynn, E. Gómez-Lázaro, and N. K. Detlefsen. 2012. "Methodologies to Determine Operating Reserves Due to Increased Wind Power." IEEE Transactions on Sustainable Energy. https://doi.org/10.1109/TSTE.2012.2208207.

Holttinen, Hannele, Peter Meibom, Antje Orths, Bernhard Lange, Mark O'Malley, John Olav Tande, Ana Estanqueiro, et al. 2011. "Impacts of Large Amounts of Wind Power on Design and Operation of Power Systems, Results of IEA Collaboration." Wind Energy 14 (2): 179 92. https://doi.org/10.1002/we.410.

Holttinen, Hannele, Michael Milligan, Brendan Kirby, Tom Acker, Viktoria Neimane, and Tom Molinski. 2008. "Using Standard Deviation as a Measure of Increased Operational Reserve Requirement for Wind Power." Wind Engineering 32 (4): 355-78. https://doi.org/10.1260/0309-524x.32.4.355.

Ibanez, Eduardo, Gregory Brinkman, Marissa Hummon, and Debra Lew. 2012. "A Solar Reserve Methodology for Renewable Energy Integration Studies Based on Sub-Hourly Variability Analysis." In The 2nd Annual International Workshop on Integration of Solar Power into Power Systems Conference. Lisbon, Portugal.

Ibanez, Eduardo, Ibrahim Krad, and Erik Ela. 2014. "A Systematic Comparison of Operating Reserve Methodologies." In IEEE Power and Energy Society General Meeting. Vol. 2014October. IEEE Computer Society. https://doi.org/10.1109/PESGM.2014.6939462.

Katz, Jessica, Paul Denholm, and Jaquelin Cochran. 2015. "Balancing Area Coordination: Efficiently Integrating Renewable Energy Into the Grid, Greening the Grid."

King, Jack, Brendan Kirby, Michael Milligan, and Stephen Beuning. 2012. "Operating Reserve Reductions from a Proposed Energy Imbalance Market with Wind and Solar Generation in the Western Interconnection." Golden, CO (United States). https://doi.org/10.2172/1046267.

Krad, Ibrahim, Eduardo Ibanez, and Wenzhong Gao. 2016. "A Comprehensive Comparison of Current Operating Reserve Methodologies.” In Proceedings of the IEEE Power Engineering Society Transmission and Distribution Conference. Vol. 2016-July. Institute of Electrical and Electronics Engineers Inc. https://doi.org/10.1109/TDC.2016.7519958.

Lew, D, G Brinkman, E Ibanez, A Florita, M Heaney, B.-M Hodge, M Hummon, et al. 2013. "The Western Wind and Solar Integration Study Phase 2." Golden, CO. 
Lu, S, PV Etingov, R Diao, J Ma, NA Samaan, YV Makarov, X Guo, et al. 2011. "Large-Scale PV Integration Study.” Richland, WA.

Ma, Jian, Shuai Lu, Ryan P. Hafen, Pavel V. Etingov, Yuri V. Makarov, and Vladimir Chadliev. 2012. "The Impact of Solar Photovoltaic Generation on Balancing Requirements in the Southern Nevada System." In Proceedings of the IEEE Power Engineering Society Transmission and Distribution Conference. https://doi.org/10.1109/TDC.2012.6281606.

Makarov, Yuri V., Pavel V. Etingov, Ning Zhou, Jian Ma, Nader A. Samaan, Ruisheng Diao, Sunita V. Malhara, Ross T. Guttromson, Pengwei Du, and Chellury Sastry. 2010. "Analysis Methodology for Balancing Authority Cooperation in High Penetration of Variable Generation.” Richland, WA (United States). https://doi.org/10.2172/974955.

Maxwell Brown, Wesley Cole, Kelly Eurek, Jon Becker, David Bielen, Ilya Chernyakhovskiy, Stuart Cohen, et al. 2020. "Regional Energy Deployment System (ReEDS) Model Documentation: Version 2019." Golden, CO (United States).

Milligan, Ela, Hein, Schneider, Brinkman, and Denholm. 2012. "Renewable Electricity Futures Study Volume 4: Bulk Electric Power Systems Operations and Transmission Planning." Golden, CO.

Milligan, Michael, Pearl Donohoo, Debra Lew, Erik Ela, Brendan Kirby, Hannele Holttinen, Eamonn Lannoye, et al. 2010. "Operating Reserves and Wind Power Integration: An International Comparison."

Milligan, Michael, Bethany Frew, Ella Zhou, and Douglas J Arent. 2015. “Advancing System Flexibility for High Penetration Renewable Integration."

Milligan, Michael, Jack King, Stephen Beuning, and Brendan Kirby. 2011. "The Impact of Alternative Dispatch Intervals on Operating Reserve Requirements for Variable Generation."

Mills, A, A Botterud, J Wu, Z Zhou, B-M Hodge, and M Heaney. 2013. "Integrating Solar PV in Utility System Operation.” Argonne, IL.

Mills, Andrew, and Ryan Wiser. 2010. "Implications of Wide-Area Geographic Diversity for Short- Term Variability of Solar Power.” Berkeley, CA. https://doi.org/10.2172/986925.

NERC. 2002. "Policy 1-Generation Control and Performance Version 2."

—. 2014. "Sanction Guidelines of the North American Electric Reliability Corporation."

—. 2016. "Standard BAL-001-2-Real Power Balancing Control Performance."

—. 2017. "Reliability Guideline Operating Reserve Management."

Neves, Diana, Miguel C. Brito, and Carlos A. Silva. 2016. "Impact of Solar and Wind Forecast Uncertainties on Demand Response of Isolated Microgrids.” Renewable Energy 87 
(March): 1003-15. https://doi.org/10.1016/j.renene.2015.08.075.

NREL. 2020. "NREL Annual Technology Baseline (ATB).” 2020. https://atb.nrel.gov/.

Ortega-Vazquez, Miguel, and Daniel Kirschen. 2008. "Optimizing the Spinning Reserve Requirements Using a Cost/Benefit Analysis." In 2008 IEEE Power and Energy Society General Meeting - Conversion and Delivery of Electrical Energy in the 21st Century, 1-1. Pittsburgh, PA, USA: Institute of Electrical and Electronics Engineers (IEEE). https://doi.org/10.1109/PES.2008.4596652.

Parsons, B, M Hummon, J Cochran, B Stoltenberg, P Batra, B Mehta, and D Patel. 2014. "Variability of Power from Large-Scale Solar Photovoltaic Scenarios in the State of Gujarat." In Renewable Energy World Conference and Expo--India. New Delhi.

Pillot, Benjamin, Nadeem Al-Kurdi, Carmen Gervet, and Laurent Linguet. 2020. “An Integrated GIS and Robust Optimization Framework for Solar PV Plant Planning Scenarios at Utility Scale." Applied Energy 260 (February): 114257. https://doi.org/10.1016/j.apenergy.2019.114257.

S\&P Global. 2018. "SNL Plant Information.” 2018. https://www.spglobal.com/marketintelligence/en/.

Samaan, N. A., Y. V. Makarov, T. B. Nguyen, and R. Diao. 2017. "Balancing Authority Cooperation Concepts to Reduce Variable Generation Integration Costs in the Western Interconnection: Consolidating Balancing Authorities and Sharing Balancing Reserves.” In , 189-226. Springer, Cham. https://doi.org/10.1007/978-3-319-55581-2_6.

Shedd, S, B.-M Hodge, A Florita, K Orwig, Sandra Shedd, Bri-Mathias Hodge, Anthony Florita, and Kirsten Orwig. 2012. "A Statistical Characterization of Solar Photovoltaic Power Variability at Small Timescales."

Sullivan, P, K Eurek, and R Margolis. 2014. "Advanced Methods for Incorporating Solar Energy Technologies into Electric Sector Capacity-Expansion Models: Literature Review and Analysis," no. July.

Westendorf, Kyle. 2018. "California Independent System Operator Corporation California ISO Flexible Ramping Product Uncertainty Calculation and Implementation Issues."

Zhang, Jie, Bri Mathias Hodge, Siyuan Lu, Hendrik F. Hamann, Brad Lehman, Joseph Simmons, Edwin Campos, Venkat Banunarayanan, Jon Black, and John Tedesco. 2015. "Baseline and Target Values for Regional and Point PV Power Forecasts: Toward Improved Solar Forecasting." Solar Energy 122 (December): 804-19. https://doi.org/10.1016/j.solener.2015.09.047. 


\section{Appendix A. Time Synchronized Load and Solar Data Set Details}

The load profiles used in our analysis are historical data from 2007-2012 that were scaled to contain an equal amount of load in each year. The full data set, which contains data originally reported on FERC Form 714 (FERC 2015), includes load from 2006-2015 and separate profiles of net energy for load for the eight BAs listed in Table 2. To avoid load growth from one year to the next unduly impacting our results, we first scaled each year's data to contain the same amount of energy as each BA's 2015 profile. Then, to better align with our starting point of all planned PV capacity (current plants plus known PV development plans), we chose 2024 as the target model year and multiplied each BA's load by the growth factor computed from dividing each BA's net energy for load in 2024 (projected) by their net energy for load in 2015 (historical) as reported in the 2019 Florida electric utilities' Ten-Year Site Plans (Florida Public Service Commission 2019). These key data points and the resulting annual net energy for load modeled for each BA are summarized in Table 4.

Table 5. Annual Net Energy for Load by BA, FERC Form 714, and Ten-Year Site Plans

\begin{tabular}{lccccc}
\hline & EIA & $\begin{array}{c}\mathbf{2 0 1 5} \\
\text { FERC } \\
\text { Load Region }\end{array}$ & $\begin{array}{c}\text { 2015 Site } \\
\text { Plan } \\
\text { (TWh) }\end{array}$ & $\begin{array}{c}\text { 2024 Site } \\
\text { Plan } \\
\text { (TWh) }\end{array}$ & $\begin{array}{c}\text { 2024 } \\
\text { Modeled } \\
\text { (TWh) }\end{array}$ \\
\hline Gainesville Regional Utilities & GVL & 1.82 & 2.02 & 1.92 & 1.72 \\
City of Tallahassee & TAL & 2.77 & 2.78 & 2.94 & 2.93 \\
JEA & JEA & 13.90 & 12.87 & 13.05 & 14.09 \\
Seminole Electric Cooperative, Inc. & SEC & 14.19 & 14.10 & 15.69 & 15.78 \\
Florida Municipal Power Agencya & FMPP & 15.28 & 17.29 & 18.18 & 16.07 \\
Tampa Electric Company & TEC & 20.11 & 20.10 & 21.50 & 21.51 \\
Progress Energy (Florida Power Corp.) & FPC & 40.87 & 42.28 & 44.81 & 43.32 \\
Florida Power \& Light Company & FPL & 122.26 & 122.76 & 123.80 & 123.30 \\
\hline
\end{tabular}

a The row for the Florida Municipal Power Agency includes OUC and Lakeland Electric load

b Corresponds to Duke Energy Florida, Inc.

Solar profiles for 2007-2012 are available on a location-by-location basis from the Renewable Resource and Power Data tool (R2PD). ${ }^{12}$ R2PD is a python interface for pulling Wind Integration National Dataset (WIND) Toolkit and Solar Integration National Dataset (SIND) Toolkit data from the DR POWER repository ${ }^{13}$ to produce aggregate, power system modelerfriendly wind, solar, and weather profiles. In our use of the tool, we provide a list of node locations and a separate list of solar capacity to place at each node. R2PD then downloads data for a non-overlapping set of SIND sites (which were prescreened for basic feasibility, consist of rural and urban sites, and number more than 155,000 across the United States) that are chosen based on a nearest-neighbor search in a manner that fulfills the total capacity request while respecting the 4-MW maximum capacity of each SIND site. R2PD then aggregates the profiles assigned to each node, saving off 5-minute time series of simulated "actual" solar generation and

${ }^{12}$ https://github.com/Smart-DS/R2PD

13 https://egriddata.org/dataset/nrel-renewable-energy-resource-data 
clear-sky solar generation, one data file per node. For our analysis, we then aggregate both the actual and clear-sky profiles to the BA level and append the time-synchronized load data.

The actual and clear-sky solar generation profiles were originally computed using the System Advisor Model (SAM) (Blair et al. 2018) and basic specifications for utility-scale fixed-tilt and one-axis tracking plants, the former for urban and the latter for rural sites (Table 6). Clear-sky generation is simulated based solely on latitude, longitude, date and time information, and plant specifications - it is the electricity output that would be expected if every day were perfectly sunny, which is a useful benchmark for understanding how actual generation compares to its theoretical maximum. Actual generation for historical conditions is simulated with the System Advisor Model using data from the National Solar Radiation Database (NSRDB) downscaled from 30- to 5-minute resolution using the methods described in Buster et al. (2021).

Table 6. PV Plant Simulation Specifications

\begin{tabular}{|l|l|l|}
\hline Utility-scale PV Plant Type & Fixed-Tilt & One-Axis Tracking \\
\hline Locations & Urban SIND sites & Rural SIND sites \\
\hline Tilt & Same as site latitude & N/A \\
\hline Azimuth & $0^{\circ}$ (South) & $0^{\circ}$ (South) \\
\hline DC-to-AC ratio & 1.1 & 1.1 \\
\hline Inverter efficiency & $96 \%$ & $96 \%$ \\
\hline Pre-inverter losses & $14 \%$ & $14 \%$ \\
\hline Ground coverage ratio & 0.4 & 0.4 \\
\hline
\end{tabular}

Solar generation is placed near BAs' transmission nodes. The node locations and categories were determined using an NREL database that merges multiple data sources that describe different aspects of the current U.S. power system, called GridDB. For this project the three key data sources available through GridDB were the Multi-regional Modeling Working Group (MMWG) 2015/2026 summer power flow case as represented in the Energy Visuals Transmission Atlas; ${ }^{14}$ the Energy Visuals FirstRate database, ${ }^{15}$ and the locations and ownership of current generators, planned builds, and retirements as represented in the SNL database (S\&P Global 2018) as of October 2018. Based on the electrical area definitions in the Transmission Atlas data, combined with the FirstRate generator data mapped to those nodes and the up-to-date status and ownership information in SNL, we were able to identify nodes associated with each BA either electrically or through generation units. We were also able to identify each BA's load nodes using the Transmission Atlas data. This process provided an overall list of the nodes associated with each $\mathrm{BA}$, as well as tags indicating the presence of existing or planned PV plants, existing or planned generation of any type, upcoming generation retirements, or load. Specific PV expansion sites were then selected by specifying which types of nodes (or all) were candidates for placement, and what percentage thereof should be randomly selected for inclusion. The ultimate outcome of this process is a list of PV expansion nodes, identified by latitude and longitude. As described in Appendix B, although there were many options for determining PV expansion nodes, this ended

\footnotetext{
${ }^{14} \mathrm{https}: / / \mathrm{www}$. energyvisuals.com/products/ta.html

${ }^{15}$ https://www.energyvisuals.com/products/firstrate.html
} 
up having negligible impact on our results. In what follows, all results were produced by randomly selecting $50 \%$ of a BA's nodes for PV expansion.

GridDB provides locations for all existing and some planned generators. We also added planned PV capacity for FMPA and JEA based on personal correspondence. Those additions consisted of three 74.5-MW FMPA plants (223.5-MW total capacity) and five 50-MW JEA plants (250-MW total capacity). FAASSTeR team members provided us with approximate planned locations and we hand-matched those to existing transmission nodes.

The PV capacity simulated per BA using the full workflow to produce synchronized load and solar datasets is summarized in Table 7.

Table 7. Summary of Modeled BA Annual Load and PV Capacity for Annual PV Generation up to $50 \%$ of Annual Load, in $10 \%$ Increments

\begin{tabular}{|c|c|c|c|c|c|c|c|}
\hline $\begin{array}{c}\text { EIA } \\
\text { BA ID }\end{array}$ & $\begin{array}{l}\text { Annual } \\
\text { Load } \\
\text { (TWh) }\end{array}$ & $\begin{array}{c}\text { Planned } \\
\text { PV } \\
\text { Capacity } \\
\text { (MW) }\end{array}$ & $\begin{array}{c}\text { PV } \\
\text { Capacity } \\
\text { (MW) to } \\
\text { Reach } \\
\sim 10 \% \text { PV } \\
\text { Generation }\end{array}$ & $\begin{array}{c}\text { PV } \\
\text { Capacity } \\
\text { (MW) to } \\
\text { Reach } \\
\sim 20 \% \text { PV } \\
\text { Generation }\end{array}$ & $\begin{array}{c}\text { PV } \\
\text { Capacity } \\
\text { (MW) to } \\
\text { Reach } \\
\sim 30 \% \text { PV } \\
\text { Generation }\end{array}$ & $\begin{array}{c}\text { PV } \\
\text { Capacity } \\
\text { (MW) to } \\
\text { Reach } \\
\sim 40 \% \text { PV } \\
\text { Generation }\end{array}$ & $\begin{array}{c}\text { PV } \\
\text { Capacity } \\
\text { (MW) to } \\
\text { Reach } \\
\sim 50 \% \text { PV } \\
\text { Generation }\end{array}$ \\
\hline GVL & 2 & 1 & 114 & 228 & 342 & 399 & 513 \\
\hline TAL & 3 & 60 & 196 & 390 & 584 & 682 & 876 \\
\hline JEA & 14 & 277 & 951 & 1,912 & 2,874 & 3,355 & 4,316 \\
\hline FMPP & 16 & 244 & 1,041 & 2,081 & 3,120 & 4,160 & 5,199 \\
\hline SEC & 16 & 2 & 987 & 1,975 & 2,963 & 3,951 & 4,938 \\
\hline TEC & 22 & 627 & 1,345 & 2,709 & 4,073 & 5,437 & 6,801 \\
\hline FPC & 43 & 304 & 2,698 & 5,396 & 8,094 & 10,792 & 13,490 \\
\hline FPL & 123 & 1,007 & 7,791 & 15,621 & 23,451 & 31,281 & 39,112 \\
\hline MUNIS & 35 & 582 & 2,297 & 4,599 & 6,900 & 9,201 & 10,352 \\
\hline FRCC & 223 & 2,520 & 14,068 & 28,173 & 42,278 & 56,382 & 70,487 \\
\hline
\end{tabular}




\section{Appendix B. Impact of PV Placement within BAs}

Although our methodology provides options for whether to place PV at relatively few or at many nodes across a BA, we found that these parameters had no discernable impact on our reserve requirement estimates. This went against our general hypothesis that geographically concentrating PV would result in more variability and uncertainty, and therefore higher reserve requirements. Although this hypothesis was supported at the inter-BA level (see Figure 4 and surrounding text), at the intra-BA level the variability and uncertainty of PV profiles was insensitive to our parameters concerning (1) at what types of nodes PV could be placed and (2) at what (randomly selected) fraction of those nodes PV would be placed. For example, we compared TAL and FPL 30\% PV results based on two methods of PV placement:

1. Installing new PV in the nodes that originally had PV installation

2. Installing new PV in randomly selected $50 \%$ of the nodes in the BA.

For TAL, option 1 placed PV at 2 nodes, versus 20 nodes for option 2. For FPL, the resulting numbers of nodes were 17 and 581, respectively. Despite the number of nodes being quite different in the two cases, these options did not have a large impact on the PV profiles, no difference was discernable in the variability statistics pulled to create ramping envelopes, and the impact on reserve requirements was therefore negligible. It is, however, unclear if this is a robust finding or an artifact of our solar data source. Because R2PD satisfies requests for PV capacity by pulling profiles for a sufficient number of gridded data sites based on a maximum of 4 $\mathrm{MW} / \mathrm{site}$, requesting profiles for a certain number of megawatts at fewer locations may still result in a similar number of profiles being pulled. There may also be significant overlap in exactly which sites are pulled, especially because although the SIND sites R2PD pulls from are a gridded data set, not all grid locations are actually available. Some were screened out for being undevelopable (e.g., park land, too steep, too wet), and others were deemed too expensive to develop compared to other locations. Unfortunately, it was beyond the scope of the study to look into these details to evaluate whether our finding is at all robust.

In any case, reserve requirement impacts are not high on the list of concerns when it comes to real-world site selection at the BA level. In addition to overall levels of solar irradiance, land cost, terrain characteristics, proximity to roads and transmission lines, local weather, and environmental and land use factors are all first-order considerations (Pillot et al. 2020; Aydin, Kentel, and Duzgun 2013; Al Garni and Awasthi 2017). 